\section{0-1995: UN RELOJ ATRASADO Y OTRO TREN PERDIDO}

\author{
Antoni Guiral \\ Guionista y divulgador
}

\section{0-1995: A SLOW WATCH AND ANOTHER MISSED TRAIN}

RESUMEN: Se trata de una época importante porque se produce una ruptura prácticamente total con una forma de entender la historieta dirigida al ocio y la educación de los lectores infantiles y juveniles. Los ecos de un cómic de autor llegan poco a poco a España, bien en tímidos intentos de autores nacionales, bien en traducciones de obras aparecidas sobre todo en Francia, Argentina e Italia. La consideración como forma de expresión narrativa y gráficamente compleja estimula el fenómeno de la investigación sobre el medio en diversas publicaciones y exposiciones, incluso en estudios semiológicos de procedencia universitaria. Ya en el tardofranquismo aparecen revistas, fascículos y libros que apuntan a la adultización del medio. Por un lado, con experimentaciones alrededor de géneros como la fantasía, la aventura o el terror y, por otro, con la aparición de un comix underground y, por tanto, contracultural autóctono. Revistas como Totem, Blue Jeans o Bumerang marcarán a partir de 1977 la pauta de la próxima revolución de la industria española. El primer desembarco compacto y real de la historieta para adultos de autoría española se produce a partir de 1978, con la aparición de la revista 1984, a la que posteriormente se unirán EI Vibora, Cimoc o Cairo.

También se atiende a la evolución del cómic infantil y juvenil, que de alguna manera, entendido como proceso industrial, finaliza en 1986 con el cierre de Editorial Bruguera.

PALABRAS CLAVE: Cómic de autor; investigación sobre el medio; obras de Francia, Bélgica y Argentina; la escuela de las agencias; búsquedas y experimentaciones gráficas y narrativas; crisis editorial; desaparición de revistas.

de la década de los cincuenta, algunos editores sagaces esquivaron la presión legal aduciendo que lo suyo era historieta para mentes formadas, acercando el formato de sus cabeceras al del libro de bolsillo y bautizándolo como "novela gráfica para adultos". Pero la evidencia era otra: aquellas historietas iban dirigidas al sector juvenil. No es que la historieta para adultos fuera una novedad -véase las tiras norteamericanas de prensa, por ejemplo-, es que faltaba reflexión, teoría y pedagogía para revalidar el medio como herramienta icónica y narrativa con la que realizar historias realmente dirigidas a mentes maduras. La teoría y la praxis de la historieta para adultos llegó tarde -pero llegó-, franqueando barreras geográficas y políticas gracias a la inquietud de ideólogos y autores. 
De Francia e Italia arribó un aire entre intelectual y reivindicativo, que supo encontrar el significado semiótico 0 narrativo de las viñetas; la historieta era un medio de entretenimiento, sí, pero también una fórmula para vehicular todo tipo de ideas. Nombres del prestigio de Alain Resnais, Francis Lacassin, Federico Fellini o Umberto Eco abanderaron la interpretación del mensaje, aportando claves académicas y científicas que trasladaron al cómic al altar de la gran cultura, descifrando su lenguaje y llevándolo a la universidad 0 a los museos. Fue esa intelectualización de la historieta la que -tarde, repito-se asimiló a trancas y a barrancas en España, generando publicaciones teóricas que, reivindicando su estatus artístico, incidieron en el trabajo de una nueva generación de historietistas quienes, amén de su juventud, almacenaban ya experiencia en su trato con mercados foráneos. El proceso de "adultización" de la historieta española iniciada poco antes de 1970 -que marcará para siempre el devenir de la industria- no puede entenderse pues sin la influencia externa y la confección de un modesto corpus teórico.

\section{EQUILIBRANDO LA BALANZA DE PAGOS}

El primer proceso migratorio de la mano de obra española de la viñeta es resultado de la guerra civil: algunos autores se exilan físicamente en Francia, deviniendo -como Cabrero Arnal o Luis García Gallo "Coq" - firmas importantes en aqueIla industria, que en los años cincuenta acogerá una segunda ola de emigrantes de la historieta, compuesta entre otros por Gabi, Julio Ribera, Francisco Hidalgo, Florenci Clavé, Antonio Parras o J osé Larraz. Si la primera generación huyó por motivos políticos, la segunda lo hizo exactamente por la misma causa, solo que esta vez disfrazada de problemas económicos. Aunque en 1956 España salía de una cruda posguerra y se encaminaba al desarrollismo económico, la miseria intelectual y moral seguía alimentando nuestras entrañas. La industria del tebeo funcionaba gracias sobre todo al liderazgo de ciertas cabeceras periódicas en formato revista -TBO, Pulgarcito- 0 cuadernillo - El Guerrero del Antifaz, Roberto Alcázar y Pedrín, Hazañas Bélicas, El Capitán Trueno-, pero los precios percibidos por los autores - por viñeta o por página- eran mayoritariamente magros. Para sobrevivir como historietista debías, en primer lugar, vender tu alma al editor, renunciando a unos derechos de autor legítimamente reconocidos en la vigente Ley de Propiedad Intelectual de 1789; en segundo término, era menester gastar coderas hasta la saciedad invirtiendo cientos de horas al mes para entregar el mínimo de páginas que garantizase una supervivencia digna y, por último, solo si eras autor de una serie muy popular o colaborador de Editorial Bruguera disponías de un buen estipendio fijo, siempre que, ojo, cumplieras a rajatabla las dos primeras premisas. Todo ello explica que muchos historietistas de entonces compaginasen su dedicación al medio con trabajos fijos en empresas públicas y privadas estables.

Pero a mediados de los cincuenta la bonanza del mercado interno empezaba a ser relativa. Las buenas e incluso excelentes ventas de algunos títulos eran indiscutibles, pero las editoriales -cuya aparición se multiplicaba por ósmosis-no cejaban en su empeño de producir la máxima cantidad de cabeceras posibles, trabajando a partir de la imitación del éxito ajeno y del ensayo-error tan poco científico y tan habitual en nuestro país. En los últimos años se había forjado una considerable cantera de dibujantes -no tanto de guionistas, que escaseaban y, además, no firmaban sus trabajos en demasiadas ocasiones-, repartidos entre un grafismo más realista y figurativo y un estilo humorístico de raíces caricaturescas. La oferta de mano de obra era amplia, lo que rebajaba sustancialmente las propuestas económicas, y para muchos dibujantes empezaba a ser compleja y agotadora la subsistencia. La solución profesional para cientos de profesionales de la historieta fue entonces el trabajo de agencia o sindicación, la "historieta de encargo".

Desde principios de la década de los cincuenta, algunos dibujantes españoles contactaron con editores y agencias de prensa europeas -británicos, franceses, belgas-, que ante la falta de dibujantes en sus países de origen y/o los económicos precios por página aceptados, encontraron en aquellas manos una verdadera mina de oro. Las dos partes salían ganando. El editor extranjero se aseguraba material de calidad gráfica para llenar sus publicaciones a un precio relativamente módico; además, los guiones eran cosa de los autóctonos, por lo que la línea editorial estaba perfectamente controlada. El agente español ofrecía trabajo a decenas 0 centenares de dibujantes -también, con el tiempo, a algunos guionistas-, que ponían todo su talento al servicio de guiones ajenos, renunciando a derechos de autor e incluso a sus originales ${ }^{1}$, pero a cambio de un trabajo continuado, estable $y$, para ellos, bien o muy bien remunerado, sobre todo en comparación con los precios que se abonaban en España. Coincidiendo con una incipiente crisis del mercado de la 
historieta de aventuras en España desde finales de los años cincuenta, las agencias ganaban no solo clientes, sino mano de obra muy cualificada, lo que permitió a muchos dibujantes jóvenes una formación continuada y remunerada y a los veteranos estabilidad económica. Las agencias españolas, instaladas en suelo propio - sobre todo en Madrid y Barcelona-garantizaban una nueva ola migratoria pero esta vez no física, sino estrictamente laboral; desde aquí las páginas llegaban a Francia, Italia, Bélgica, Gran Bretaña, Alemania, Holanda, Estados Unidos o Sudáfrica.

La paulatina incorporación de dibujantes muy jóvenes en el ínterin de las agencias -aprendices en el sentido más literal del término-, garantizaba la continuidad de una oferta que cada vez más adquiría fama de puntualidad y calidad entre los editores extranjeros. Fueron muchos de estos dibujantes los que, al principio desde trabajos de encargo y luego ya por iniciativa propia, labrarían el terreno para la historieta de autor en España. Y lo hicieron con el bagaje y la seguridad que les reportó la experiencia en el terreno de la historieta de género por encargo, pero también desde la curiosidad y la inquietud de unos profesionales que observaban de cerca la evolución del medio propiciada en Francia y en Italia. Allí, sin el peso amoral de la dictadura, periodistas, sociólogos, semiólogos, autores y editores iban madurando otras formas de entender la historieta, ahora más compleja, más comprometida con la sociedad, aunque también más experimental, con todo lo bueno -hallazgos a desarrollar, enriquecimiento formal y narrativo- y lo malo -experiencias fallidas, falsa ampulosidad, predominio de la estética-que ello conlleva.

Por otra parte, el asentamiento de las agencias españolas en el mercado internacional favoreció la mayor participación de los guionistas españoles, que junto a dibujantes de los estudios y con el amparo del agente, producían series adaptadas a las exigencias del mercado en el que se movían. Miquel Cussó, Carlos Echevarría, Flores Thies, Mariano Hispano, Andreu Martín, Manuel Medina, Víctor Mora, Francisco Pérez Navarro, Pedro Quesada, Enrique Sánchez Pascual, Enrique S. Abulí o Juanjo Sarto escribían historieta de género en algunos casos contaminada por una cierta ansia autoral, aspiración complementada por dibujantes como Josep Maria Beà, Jordi Bernet, Víctor de la Fuente, Fernando Fernández, Alfonso Font, Luis García, Carlos Giménez, Esteban Maroto, Suso Peña, Miguel Quesada, Enric Sió, Ramón Torrents o Adolfo Usero. Es precisamente de algunas de estas experiencias que surgen los primeros títulos aparecidos en España de un cómic más inquieto e incluso experimental, no revolucionario pero sí más atento al desarrollo social y político, lo que se traduce en una revisión de los antiguos esquemas argumentales de la clásica historieta de aventuras española.

Si para una primera generación de dibujantes realistas las referencias estaban en la prensa diaria norteamericana -Milton Caniff, Stan Drake, Hal Foster, Clarence Gray, Alex Raymond-, aquellos nuevos valores forjados en las agencias, sin renunciar a los clásicos, bebían de otras estéticas más rompedoras y contemporáneas procedentes sobre todo de Francia y Bélgica -Guido Crepax, Dino Battaglia, Hugo Pratt, JeanClaude Forest, Guy Peellaert, Philippe Druillet-, aunque también de Argentina -Alberto Breccia-. Uno de los primeros en comprender la revolución estética y narrativa de aquella historieta fue Enric Sió, que ya en 1967, con guión del escritor Emili Teixidor, ilustró Lavínia 2016 o la guerra dels poetes, una fábula política de llamativa estética aparecida en la revista publicada en catalán Oriflama, que como otras iniciativas de la prensa en esta lengua vernácula -Cavall Fort, L'Infantiltuvo que asociarse a la Iglesia catalana para ver la luz en tiempos oscuros. Sió no tardó en emigrar primero a Italia y luego a Francia, donde desarrolló una obra densa, compleja y muy personal que exigiría una merecida reivindicación.

\section{PARTIENDO de MOdelos FORÁNeOS}

No es casual que las primeras publicaciones españolas teóricas de cómics surgidas a imitación de publicaciones francesas como Giff Wiff (1962) o Phenix (1966), aparezcan a finales de los años sesenta, justo cuando nuestro por entonces cansado y despistado mercado de la historieta ofrece visos de renovación. Cuto (1967) o Bang! (1968) son fanzines, revistas confeccionadas de forma precaria por aficionados al medio cuya formación les lleva a profundizar en una historieta que ya se ha hecho adulta. En realidad, en 1968 la industria del cuadernillo o tebeo apaisado ya es historia: títulos tan significativos como El Guerrero del Antifaz o Hazañas Bélicas habían desaparecido en 1966, y El Capitán Trueno cerraría su larga trayectoria precisamente en 1968; solo Roberto Alcázar y Pedrín, entre las cabeceras más longevas, llegaría hasta 1976. Mientras los tebeos de humor sobrevivían con mayor o menor solvencia con TBO o las revistas de Bruguera y Valenciana, la historieta de aventuras 
languidecía, sustituida en parte por los llamativos colores y las fantásticas y bizarras páginas de los comic-book de origen norteamericano que la editorial mexicana Novaro importaba y distribuía en España. Fue la editorial barcelonesa Íbero Mundial de Ediciones -especializada en cuadernos de romance y aventuras pero editora también de la revista de humor Mata Ratos- la primera en aprovechar la parca liberalización que ofrecía el sello "para adultos" en portada, y lo hizo con dos productos "de agencia" abiertamente inspirados por el auge del género fantástico.

Si la revista Dossier Negro (1968) presentaba material de una calidad gráfica más que digna aunque con un concepto del terror todavía bastante clásico, la aparición de la colección

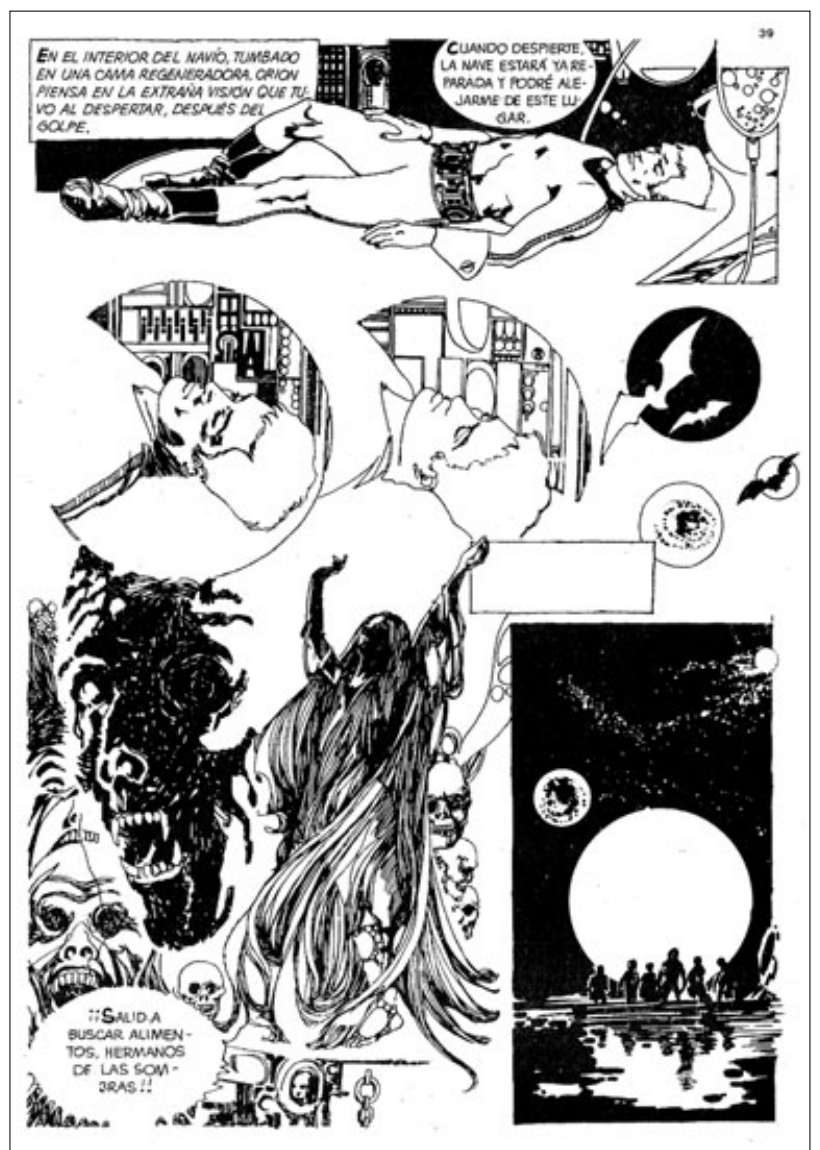

Imagen 1. Página de Esteban Maroto para un episodio de 5 por Infinito publicado en el $n^{0} 15$ (1970) de Delta 99; obsérvese la disposición abierta de las viñetas y los recursos gráficos utilizados para ambientar la plancha.
Delta 99 (1968) supuso el primer paso para la implantación de una historieta realmente adulta en España. La inclusión de dos series producidas por la agencia Selecciones Ilustradas -Delta 99 y 5 por Infinito- dejan entrever que los jóvenes creadores se habían desposeído del clasicismo que había marcado nuestra historieta figurativa para entrar en una nueva dinámica. Tanto Flores Thies, Víctor M ora, Carlos Giménez, Adolfo Usero con Delta 99 y Esteban Maroto, Ramón Torrents, Luis García y Suso Peña con 5 por Infinito evidenciaban que aquellas series de ciencia-ficción no respondían al canon habitual de una mera space-opera. Mientras la primera actualizaba en España el concepto de cómic de aventuras con una narración muy dinámica y un concepto gráfico más sofisticado, la segunda iba un paso más allá, rompiendo la clásica estructura estética de la página con efectos visuales renovadores e incorporando un cierto misticismo en sus guiones. En 1969, Mora y Giménez continuaron explorando el universo de la ciencia-ficción con Dani Futuro, serie aparecida en la revista juvenil Gaceta Junior, que dentro del terreno del humor aportó interesantes entregas de creadores como Chiqui de la Fuente, Bernet Toledano o Jan. Dani Futuro supone por un lado la madurez estilística de un Carlos Giménez de grafismo entre realista y caricaturesco, de trazo sintético y certero, que actualiza a la vez que renueva el clasicismo gráfico de la historieta de aventuras con una puesta en escena muy trabaja$\mathrm{da}$, y que se plantea el uso sintáctico de la narrativa analítica y de la composición de página. Por otro lado, esta serie redescubre a un Víctor Mora concienciado política y socialmente, más libre y dinámico en sus planteamientos narrativos. En 1971 Dani Futuro, tras la desaparición de Gaceta Junior, pasará a ser publicada en el semanario belga Tintin, aumentado la nómina de creadores españoles que trabajan desde España directamente para el mercado franco-belga, entre los que se hallaban Miquel Cussó, Jordi Bernet, Jesús Blasco, Tomàs Marco, Jaume Brocal Remohí o Claudio Tinoco, y a los que pronto se añadirá Luis García?2.

\section{El EJEMPLO de 'TRINCA'}

Muy lentamente, esa historieta firmada por autores del país, más contemporánea y en formación, más ambiciosa en sus planteamientos gráficos y literarios, iba afianzándose en España. Hasta ahora hemos citado títulos más próximos a una historieta juvenil avanzada que dirigidos a lectores adultos; es el caso de la revista Trinca, aparecida 
en 1970 y publicada por la Editorial Doncel. Pero Trinca aportó algo más a esta nueva historieta: aun dirigida a lectores jóvenes, forjó una filosofía propia, agrupando en sus páginas autores inquietos que unían a sus capacidades una aspiración autoral, de historieta más personal. No deja de ser irónico que la publicación estandarte de un concepto de historieta más abierta -e incluso mínimamente comprometida a nivel social-, partiera de una editorial concebida por la Delegación Nacional de Juventudes. Esta entidad, forjada en el Frente de Juventudes - constituido en 1940 como una sección del partido político Falange Española Tradicionalista y de las JONS-, tenía como principal objetivo el adoctrinamiento en la ideología fascista de los jóvenes españoles. Algo menos politizada a partir de finales de los años cincuenta, en 1959 fundó Editorial Doncel, constituida para la edición y distribución de libros divulgativos y formativos. Al aparcar -al menos parcialmente-la orientación política, Doncel constituyó un interesante fondo de libros de texto y de literaria infantil y juvenil, con una estupenda selección de escritores e ilustradores. Cuando abordó la historieta -a la que ya había dedicado un par de libros teóricos en 1963 y 1964-, demostró de nuevo un alto nivel de exigencia, tomando como claro referente a un mensual de cómics nacido en Francia en 1959, que se había tornado en la exégesis de la renovación de las viñetas de género: Pilote.

Pilote recogió el testigo de ambiciosas y altamente cualificadas publicaciones infantiles franco-belgas como Spirou, Le Journal de Mickey o Tintin, cultivando una historieta juveniladulta que mantuvo fija la atención de las generaciones que habían crecido con aquellas revistas en este medio de comunicación. Fue una revista- puente, abierta a series humorísticas -Astérix, Iznogoud-y realistas -Blueberry, Valerian-, que contribuyó a la "adultización" del medio con sus relecturas del humor y de la aventura, incorporando visiones más sociales y políticas así como secciones de texto divulgativas centradas en cuestiones ligadas a la realidad del momento. Sin llegar a estos extremos, Trinca cumplió de alguna manera con ese objetivo, ya que recuperaba o mantenía en la historieta a los lectores de TBO, Bruguera o Valenciana. Es más, la estructura de Trinca era muy semejante a la de Pilote -a excepción de los temas tratados en sus secciones divulgativas $^{3}-$, y el espíritu de sus historietas respetaba los principios de calidad y modernidad de su precedente francés. Trinca, siempre bajo el epígrafe de "producto juvenil", abría sus páginas a series humorísticas y realistas, potenciando a personajes fijos sin olvidar historietas cortas y completas o relatos más largos de argumento único. También supo mezclar la renovación del clasicismo con aportaciones más rompedoras -tanto estéticamente como en sus contenidos-, y en su perfeccionista selección de colaboradores incorporó tanto a veteranos de otras lides como a jóvenes representantes de una historieta más actual, procedentes de la industria nacional y del cómic de agencia. Y con material original de primera mano, realizado ex profeso para la revista, lo que recuperaba la esencia de la mayoría de cuadernillos y revistas autóctonas aparecidas entre los años treinta y sesenta.

Entre 1970 y 1973 Trinca rompía moldes en la industria de la historieta española con aportaciones de humoristas reconocibles en Bruguera, Valenciana y Ediciones TBO como Cubero, Rojas de la Cámara o Bernet Toledano; recuperaba del exilio firmas como las de Juan Arranz, José Bielsa, Víctor de la Fuente -en su primer acercamiento a una historieta autoral y densa con Haxtur-, Gabi o Carlos Cruz; abría sus páginas a jóvenes creadores que buscaban romper moldes acercándose a estéticas figurativas -Alfonso Azpiri-, caricaturescas -Ventura y Nieto, subversivos renovadores del humor surrealista con Es que van como locos 0 Maremágnum-e inclasificables -Miguel Calatayud, autor avanzado a su tiempo con una muy personal narración visual volcada en Peter Petrake y Los doce trabajos de Hércules-; asumía los nuevos trabajos de colaboradores de cuadernillos como Buylla o Antonio Hernández Palacios - dotado de una impactante puesta en escena con Manos Kelly y El Cid y futuro colaborador del mercado francés- 0 de animadores recién llegados del exilio cubano, como Jan -creador de Superlópez en 1973, serie posteriormente popularizada en las revistas de Bruguera-; publicaba autores extranjeros como el chileno Arturo del Castillo -maestro en la ambientación del western-, y dejaba una cierta libertad formal a inquietos dibujantes de agencia como Carlos Giménez, Adolfo Usero, Suso Peña, Esteban Maroto, Brocal Remohí o Leopoldo Sánchez, así como a guionistas especializados también en material de sindicación, como Sánchez Pascual, Sánchez Abulí, Mariano Hispano o Andreu Martín.

Otro importante revulsivo para asentar la creciente presencia de una historieta para adultos en un paupérrimo todavía mercado español de la historieta figurativa de género - de la humorística nos ocuparemos más tarde-, procede del mercado norteamericano, pero no del comic-book, sino del pequeño zulo ocupado por los magazines en blanco y negro. 
Fue de nuevo la ya citada editorial Íbero Mundial de Ediciones la que adquirió los derechos para España de las revistas de cómics de terror, fantasía y ciencia-ficción del editor James Warren -Creepy (1964), Eerie (1966) y Vampirella (1969)-, publicando primero Vampus (1971) y, posteriormente, Rufus (1973) y Vampirella (1974, esta editada por Garbo). Warren había sorteado en EE UU la censura previa ejercida por la propia industria por mediación del Comics Code, renunciando para ello al formato de comic-book y acogiéndose al de revista periódica, lo que le permitía publicar historietas para adultos. Aunque con censura y recortes -básicamente en las formas femeninas-, la edición española de aquellas historietas no descubrió una fórmula más libre de abordar el medio, especialmente en su vertiente fantástica. De paso, aquellas revistas permitieron a muchos jóvenes dibujantes españoles -que colaboraban en ellas desde 1970 por mediación de la agencia Selecciones llustradas- encontrar un espacio abierto a la experimentación, que además de exigir un alto nivel de dedicación y calidad les permitía crecer como profesionales, hasta el punto de que muchos de ellos serían la punta de lanza del boom de la historieta de autor para adultos iniciado en 1979. El éxito comercial de estas publicaciones, más el de la ya citada Dossier Negro, provocó la aparición de incontables imitadoras publicadas por varias editoriales españolas, que junto a versiones de material producido por Marvel o DC Comics, aunó propuestas confeccionadas por historietistas del país que, en muchos casos, sirvieron para iniciar nuevas carreras profesionales.

\section{BURU LAN}

Otro título importante para esta nueva historieta que, poco a poco, estaba empezando a aparecer en España fue Drácula, en realidad una colección de fascículos de 28 páginas que

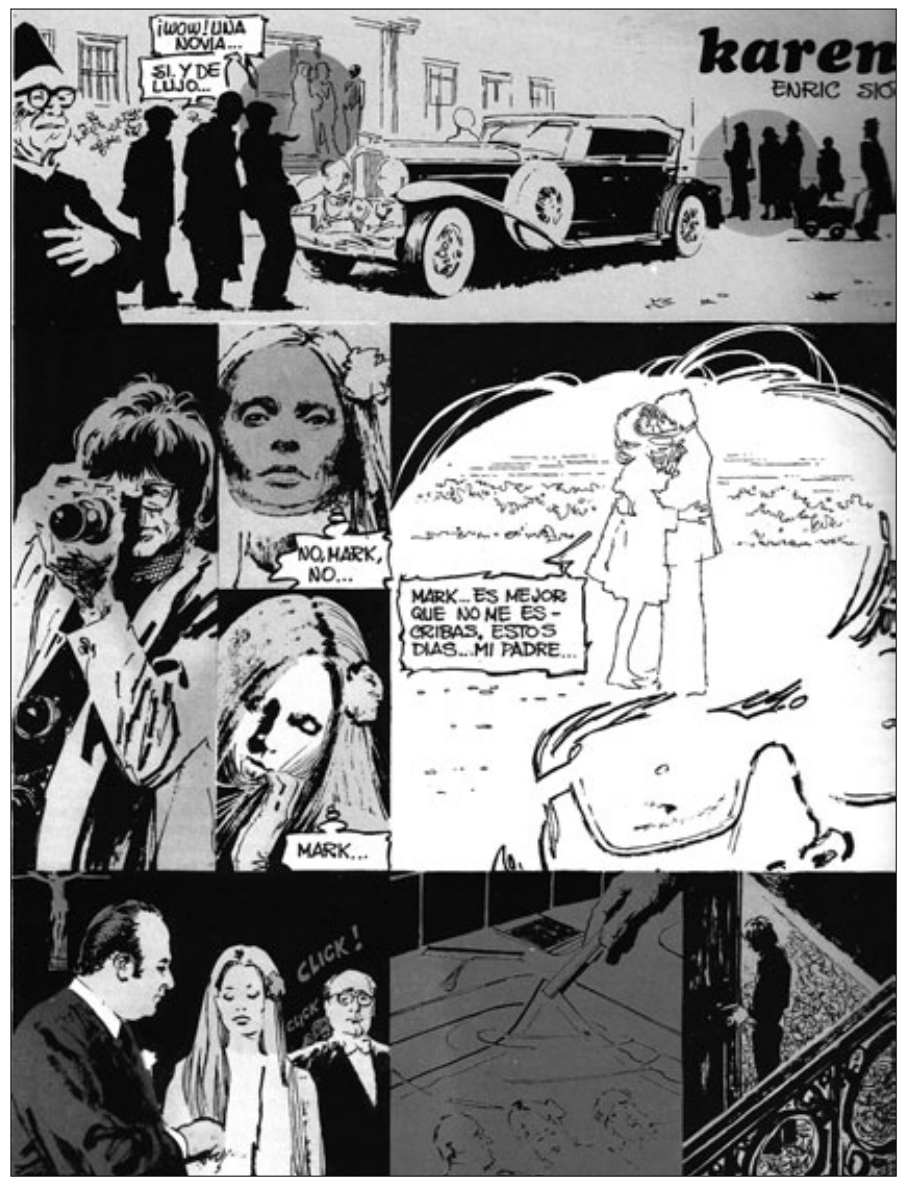

Imagen 2. En "Karen", historieta perteneciente a la serie Mis miedos (Drácula, $n^{\circ}$ 5, 1971), Enric Sió utiliza técnicas próximas a la fotografía quemada y un montaje analítico para narrar la acción. 
aunque no consiguió superar los 12 números hizo de la experimentación estética y narrativa una de sus banderas. Drácula fue publicada en 1971 por la editorial Buru Lan, fundada por uno de los más destacados teóricos de la historieta española, Luis Gasca, en 1970. Aunque en su relativamente corta existencia -de 1970 a 1976- se ocupó sobre todo de editar versiones españolas de fumetto italiano -Tex, Zagor-, bande dessinée franco- belga -Rahan-, tiras británicas - James Bond y Modesty Blaise- 0 comic strips norteamericanas -El Hombre Enmascarado, Rip Kirby, Príncipe Valiente, Ben Bolt, Carlitos, BC, Johnny Hazard-, Buru Lan apostó con Drácula por la historieta española. Aquellos fascículos eran decididamente lectura para adultos, con la escasa permisividad que permitía una dictadura que controlaba la Ley de Prensa e Imprenta de Fraga y que permanecía atenta a desmanes políticos y/o sexuales. Drácula integró series concentradas en el género fantástico con, en algunos casos, atisbos de denuncia social y política. Junto a relatos escritos por Juan Tébar, Luis Vigil, Carlos Buiza o J osé Luis Garci -sí, el director de cine-, aparecieron series como Drácula -parodia humorística de Alfons Figueras-, Mis miedos -historietas de compleja narración y estética experimental de Enric Sió- y trabajos de fantasía y terror psicológico de Esteban Maroto, Sadko, Alberto Solsona, Josep María Beà, Carlos Giménez, Manuel López Blanco, Vigil y Garci. Solo fueron 12 números, pero ayudaron a evidenciar que la historieta española quería romper con el pasado de forma contundente, aunque todavía no poseía la infraestructura, experiencia y, por supuesto, libertad necesaria para explotar; 12 números en los que, por cierto, llamaba la atención la libertad cromática aplicada a las historietas, en ocasiones cercana al kitsch 0 al pop. En 1972 Buru Lan volvió a lanzar la colección Drácula, reeditando estas doce entregas y ampliándola con una nueva edición de las historietas de Delta 99 y 5 por Infinito.

Pero Buru Lan no se contentó con publicar fascículos o colecciones monográficas, también importó un nuevo tratamiento en la edición de revistas, iniciado concretamente por la publicación italiana Linus (1965). Originalmente, se trataba de, junto a obras de autores autóctonos emergentes, presentar series extranjeras de cómics de prestigio, tanto clásicas como contemporáneas. El Globo y Zeppelin, las dos revistas de Buru Lan, distintas en tamaño pero idénticas en su filosofía, apenas se ocuparon de creadores españoles -algunos textos y la publicación de una historieta de aventuras de Antonio CarriIlo-, pero fueron claves en el sentido de recuperar y divulgar algunas series clásicas de la prensa norteamericana -Little
Nemo in Slumberland (Winsor M cCay) Li'I Abner (Al Capp), The Spirit (Will Eisner), Dick Tracy (Chester Gould) o Pogo (Walt Kelly)-, descubrir al lector y al profesional de nuestro país tiras poco 0 nada conocidas en España, tanto norteamericanas - El Mago de Id (Brant Parker y Johnny Hart), BC (J ohnny Hart), Big George (Virgil Partch), Miss Peach (M ell Lazarus) 0 Feiffer (Jules Feiffer)-, como sudamericanas -Mafalda (Quino), Mi amigo el canguro (Ziraldo)-, italianas -Strumtrumppen (Bonvi)- o británicas - Andy Capp (Reg Smythe), Tiffany Jones (J enny Butterworh y Pat Tourret), Modesty Blaise (Peter O'Donnell y Jim Holdaway) y James Bond (Jim Lawrence y Yaroslav Horak)-. Al mismo tiempo, El Globo y Zeppelin incluían un importante apartado literario, destinado a glosar las excelencias de las historietas que publicaban, pero también a divulgar la historia de los cómics; y, last but not least, nos descubrieron trabajos de algunos de los más importantes renovadores de la historieta mundial, como H. G. Oesterheld,

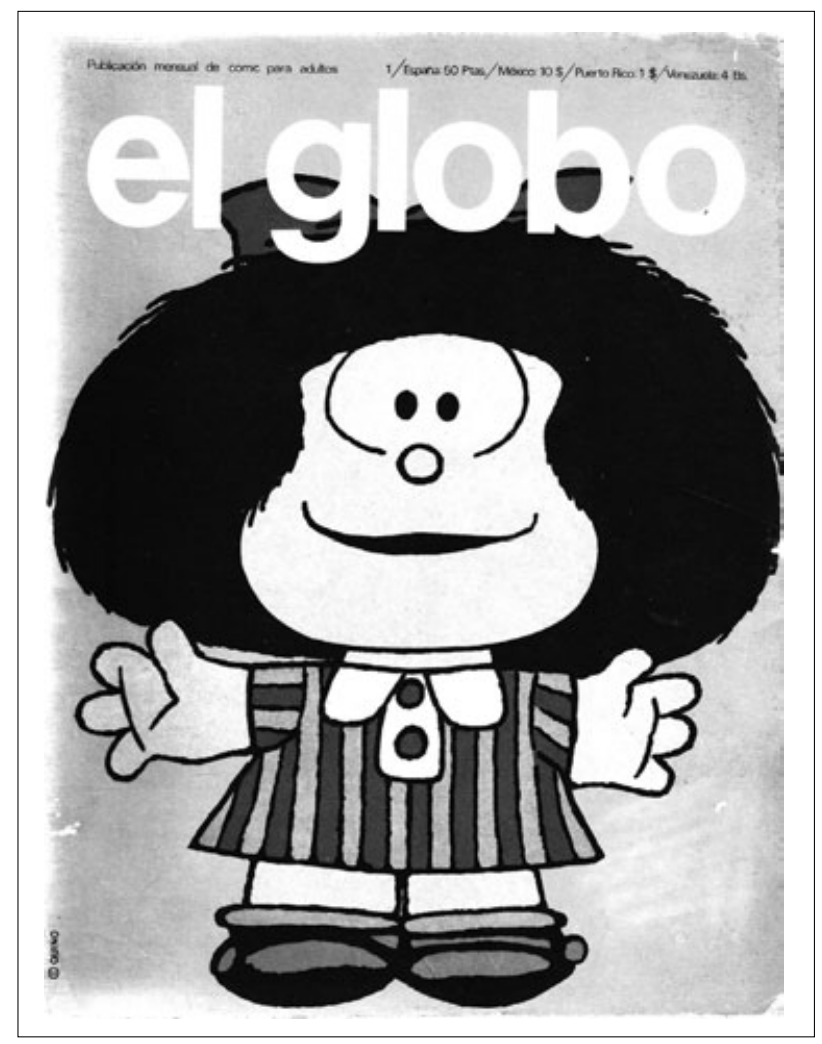

Imagen 3. Mafalda, de Quino, era la protagonista de la portada del $n^{\circ} 1$ de El Globo (1973), una revista que aunaba información teórica $y$ entrevistas con autores con una selección del mejor cómic internacional del momento. 
Alberto Breccia, Guido Crepax, Hugo Pratt - Corto Maltés- 0 Dino Battaglia. Buru Lan, por tanto, comercializó por primera vez en España un compendio internacional de primera línea en lo que a la "nueva historieta" se refiere, una excelente selección de material apoyada por un cuerpo teórico complementario que revalorizaba el contenido social e intelectual que los cómics siempre habían poseído, pero que ahora se ordenaba, clasificaba y estudiaba para una mejor comprensión. Y aunque algunos historietistas más maduros mostraban una cierta indiferencia a la "intelectualización" del medio, los más jóvenes tomaban nota de las enseñanzas de aquellos creadores franceses, italianos, americanos y británicos, aprendiendo técnicas gráficas y narrativas pero también imbuyéndose de una fórmula nueva de afrontar los contenidos de sus obras.

\section{El 'COMIX' es PARA ADULtos}

De hecho, y aunque con los cortapisas impuestos por la situación política del país, España entraba poco a poco en la modernidad de la historieta: exposiciones de cómics en museos, publicaciones teóricas, tesis universitarias e incluso gérmenes de sindicatos como DHIN (Dibujantes de la Historieta y la llustración Nacionales) -que concienciaron a la profesión de sus derechos y obligaciones-, evidenciaban que, aunque minoritario, el movimiento para la revalorización de la historieta era un hecho en nuestro país. La otra gran influencia para dotar de un lenguaje gráfico y literario adulto y de clara índole social a los cómics llegó a nuestra historieta en 1973, procedente del comix underground norteamericano. Surgida y madurada en Estados Unidos en revistas universitarias, publicaciones alternativas y comix-book en la primera mitad de los años sesenta, la historieta contracultural quebró las bases del cómic estándar, potenciando el blanco y negro, las historias cortas, un grafismo más libre y personal -feísta incluso-y, sobre todo, la voluntad de llegar a un lector nuevo, adulto, con argumentos de claro tinte social y político, críticos con el sistema; reflejo de una realidad palpable, al menos en la sociedad norteamericana, donde la revolución sexual, las drogas y las reivindicaciones por una nueva ética social estaban a pie de calle. Una dictadura no permite desarrollar tales conceptos, pero sí asimilarlos y adaptarlos. Fue en 1972 y 1973 cuando una versión española permisible de aquel comix llegó a las librerías de la mano de Editorial Fundamentos, que publicó dos volúmenes titulados Comix Underground USA, con una selección de material encabezada por, entre otros, Robert
Crumb, Gilbert Shelton o Victor M oscoso. En 1973 aparece la primera publicación alternativa española, El Rrollo Enmascarado, firmada por autores jóvenes como Nazario, Mariscal, Miguel y Josep Farriol, Max, Pàmies, Roger o Isa, creadores que querían contar sus propias historias sin trabas, narrar con humor aquello que vivían y que pasaba en la calle y exponer con entera libertad sus historietas provocadoras, críticas 0 sarcásticas, sin atender a presiones editoriales 0 comerciales. No voy a extenderme más en este aspecto, importante, que favorece la génesis de un cómic adulto y autoral en España, ya que del comix underground se ocupa con mucho mejor criterio quien mejor conoce el tema, Pablo Dopico, en otro artículo de esta revista.

Paralelamente al despliegue del underground autóctono, un semanario de humor, Mata Ratos, emprende una etapa muy cercana en espíritu al comix, forzando la permisividad en cuestiones sociales y políticas del momento con autores como Tom, Romeu, Vallés, Fer, Joma, Alfonso López, Max o Roger. Y ello nos lleva a recordar que solemos pasar por alto la historieta humorística aparecida en semanarios de humor satírico, cuando -conviene recordarlo-, este medio se desarrolló en realidad en la prensa humorística para adultos en el siglo XIX. Durante los primeros años de la época que nos toca retratar, algunas de esas publicaciones ya incluían en su contenido historietas de humor social y político que inciden, también, en el desarrollo del medio en nuestro país. En cabeceras como Por favor, Muchas Gracias, Barrabás o El Papus -y posteriormente por supuesto en EI Jueves O TMEO - los humoristas también desarrollan sus propuestas en formato de historieta, dirigiéndose claramente a un lector adulto en viñetas narrativas, básicamente con el trabajo de creadores como Óscar, Ivà, Ventura y Nieto, Carlos Giménez, Ja, Manel, Gin, García Lorento, Manel, Tha, L'Avi Alfonso López, Fer, Tom o Joma.

\section{EN TRANSICIÓN}

En 1975 el dictador se resiste a mori;; su régimen dictatorial, aunque en la UVI también: intenta seguir controlando el destino del país, publicaciones con viñetas incluidas. Es por este motivo que la aparición de una revista referente en lo que a la historieta social se refiere, Butifarra (1975), tendrá que ser confeccionada con escasos medios y ser distribuida de forma semiclandestina en el cinturón industrial de Barcelona. La historieta tiene un uso social evidente, y 
los colaboradores de Butifarra la toman como referencia para denunciar los abusos de ayuntamientos y otras instituciones públicas y privadas. Con el apoyo de las asociaciones de vecinos en una Barcelona muy activa en sus reivindicaciones democráticas, Butifarra lidera esa historieta de denuncia que pone en solfa el sistema autárquico y a sus principales valedores. Con humor, sarcasmo e ironía, pero también con espíritu divulgativo y con historietas de corte gráfico más realista, la ideología progresista se asienta en las viñetas de muchos creadores que ya hemos citado en otras de sus propuestas profesionales, como Carlos Giménez Adolfo Usero, Luis García, Jan, Carlos Vila, L'Avi, Alfonso López, Ricard Soler, Ventura, El Cubri, Gin, Max, Azagra, Carulla, Lluís Miracle, Juanjo Sarto, Montse Clavé o Marika. Sin abandonar sus espíritus combativos y sabedores sus responsables del analfabetismo democrático del país, Butifarra iniciará en 1977 una nueva etapa como revista de distribución nacional con el sello de Iniciativas Editoriales, una etapa en que la historieta, amén de su valor ideológico, tomará un claro acento pedagógico.

En aquella inquieta trastienda de la transición y el nacimiento de la democracia en España, aparece precisamente en 1976 y en una revista humorística -Muchas Gracias- la serie Paracuellos, escrita y dibujada por Carlos Giménez. De alguna manera, Giménez - dibujante de agencia pero también, como hemos visto, ambicioso creador de nuevas fórmulas historietísticas-, se avanza en la construcción de una historieta personal que recupera la memoria histórica con una serie que retrata la vida de los niños encerrados en el Auxilio Social del franquismo más duro. Considerada por méritos propios como una de las obras cumbre de la historieta internacional contemporánea, Paracuellos transmite ternura, odio, rencor, amor, impotencia, miedo y humor en sus muy bien compuestas y desgarradoras páginas, gracias a la inteligencia de un autor que ha madurado narración, tempo, dibujo y capacidad literaria a partes iguales. Y si Paracuellos fue publicada inicialmente en 1976 en un semanario de humor -luego en una revista erótica, Yes, y finalmente en libro-, fue porque la industria todavía no había madurado el formato con el que vehicular la historieta de autor, lo que aún tardaría dos años en llegar.

Precisamente, una de las primeras intentonas por asumir ese cómic más social y político enfocado en el costumbrismo, la sátira, la crítica, la reivindicación y hasta el marxismo históri$\mathrm{co}$, se concentra en la iniciativa de otro grupo de historietista

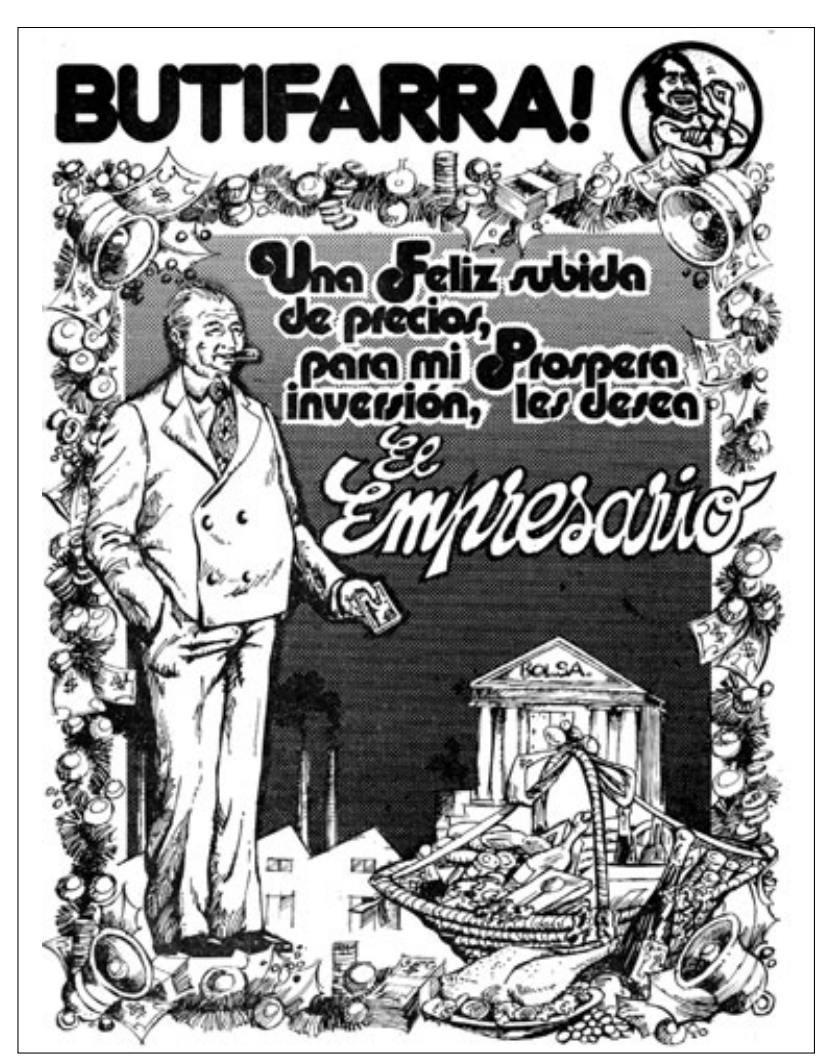

Imagen 4. Una de las portadas de la primera etapa de Butifarra! (1975), boletín informativo y crítico con historietas que denunciaban los abusos de instituciones públicas y privadas, $y$ que fue distribuido

de forma semiclandestina en su momento.

españoles, que con el nombre de Colectivo de la Historieta pone en marcha la revista Bang! Trocha en 1977. Ahora y aquí se trata de profesionales en plenas facultades artísticas conscientes del valor pedagógico y social de la historieta, que con su trabajo buscan revalidar la madurez del medio al tiempo que divulgar una forma de entender la sociedad abierta y plural, siempre desde una perspectiva progresista, reivindicando las taras y los problemas del día a día y de cómo estos inciden en las personas. El grupo, heterogéneo, procedente del humor gráfico, la historieta por encargo o el cómic claramente politizado, está formado entre otros por guionistas y dibujantes como Perich, Alfonso López, Cánovas, Ventura, Alfonso Font, Usero, Nieto, Andreu Martín, JuanJo Sarto, Armonía Rodríguez, El Cubri (Felipe Hernández Cava, Pedro Arjona y Sarturio Alonso), Luis García, Jaume Marzal, Montse Clavé, Marika o Mariel Soria, con la incorporación de teóricos como Ludolfo Paramio o Antonio Martín. La experiencia es relativamente 


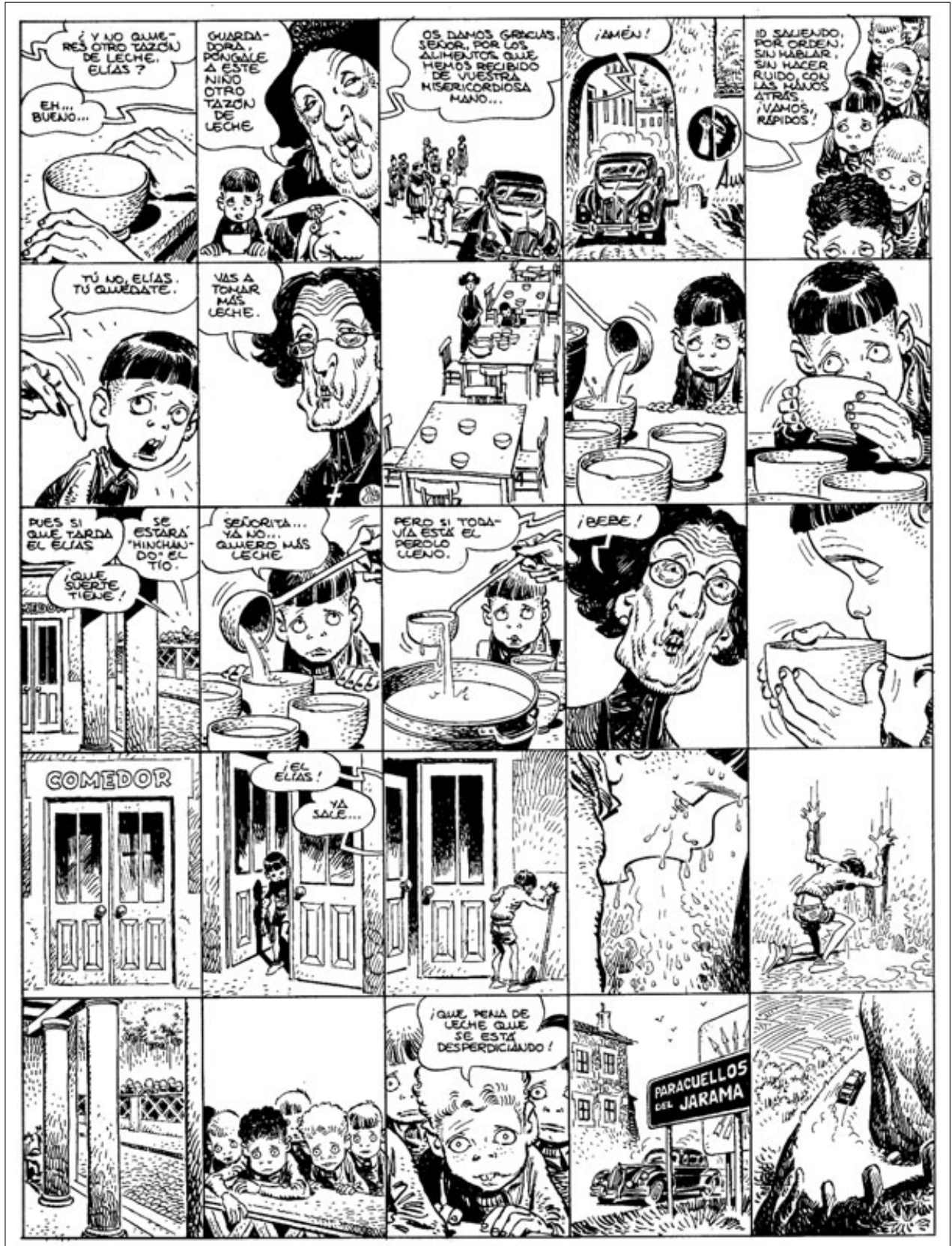

o cultural, como La Calle, donde en 1978 aparecerán series como Tequila Bang -de Víctor Mora y Alfonso Font-, que apuesta por un argumento de acción y aventuras crítico y progresista con protagonismo femenino, o las aportaciones de El Cubri, tres autores con vocación experimental que profundizan en las capacidades expresivas y sociopolíticas del medio.
Imagen 5. Paracuellos, una de las mejores obras de la historieta contemporánea, fue iniciada por Carlos Giménez en 1976; su creador aportó una fórmula gráfica y narrativa renovadora, en la primera aproximación de la democracia a nuestra memoria histórica. 
Todas estas iniciativas encierran un hecho que a primera vista podría pasar desapercibido, pero que disfrutó de notables aportaciones a la lectura reivindicativa de la historieta: se trata de la presencia de autoras de cómics que utilizan su trabajo para evidenciar el rol impuesto a la mujer por la sociedad y también para ejercer una postura crítica respecto al machismo imperante. Si hasta entonces las relativamente pocas historietistas -en comparación con los hombres- se habían tenido que contentar con la realización de tebeos sentimentales 0 trabajo de encargo para agencias, fue en aquel momento histórico de nuestro cómic cuando no solo por su trayectoria profesional, sino por su capacidad crítica y actitud personal, las autoras emergen con un mensaje crítico complementario al de sus homónimos masculinos. Ya desde finales de los años sesenta Núria Pompeia había demostrado en publicaciones como Oriflama o Triunfo su inquietud por una historieta transgresora en formas y contenidos, denunciando la sumisión social de la mujer, un trabajo que sería continuado desde mediados los años setenta por creadoras como Marika, Montse Clavé, Mariel Soria o Laura.
Imagen 6. Portada del $n^{o} 1$ de Bang! Trocha (1977), revista de inspiración colectiva con historietas críticas de origen social y político, realizada por autores conscientes de la madurez del medio para narrar todo tipo de historias.

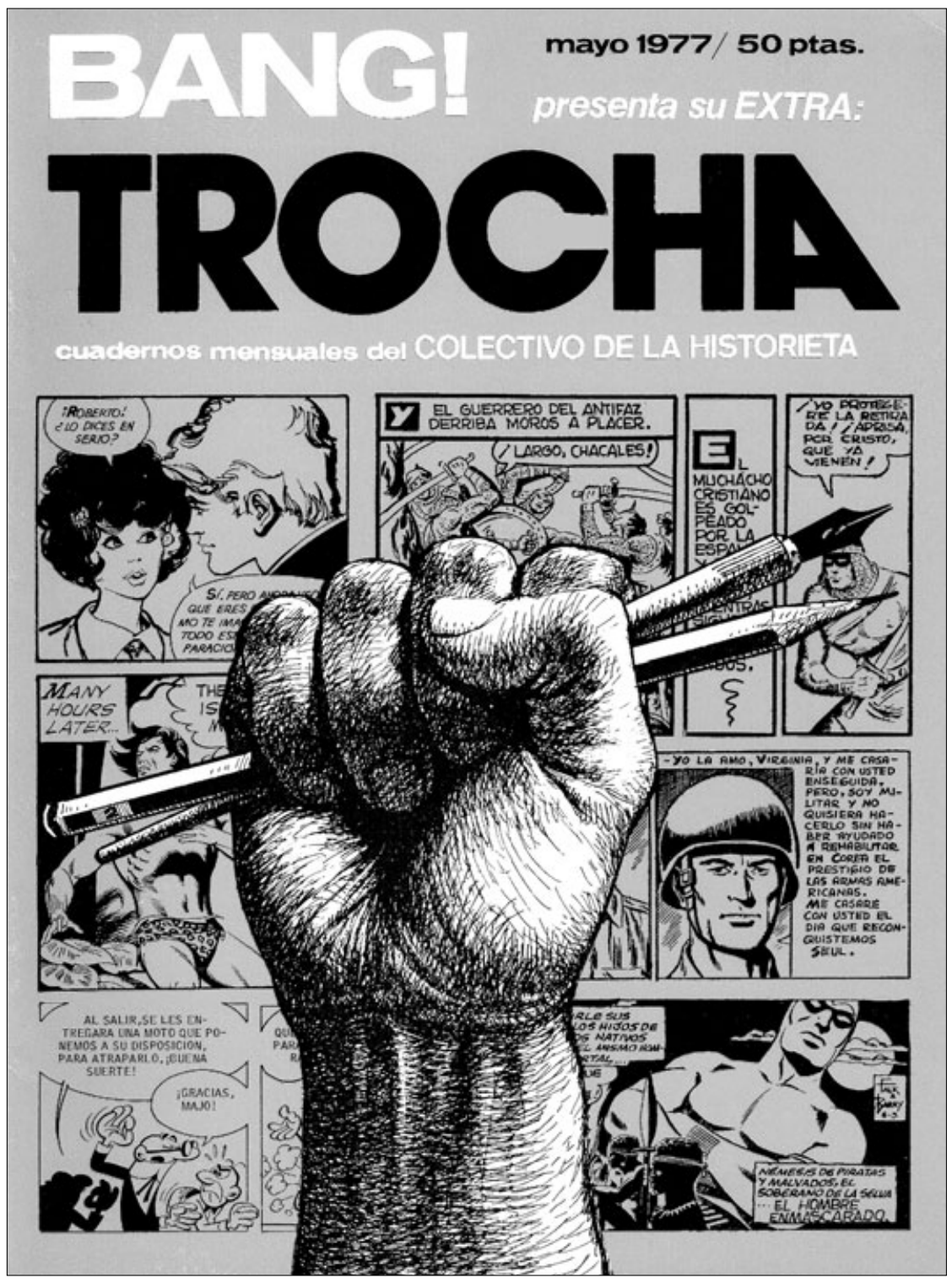

ARBOR CLXXXVII 2EXTRA 2011 183-208 ISSN: 0210-1963

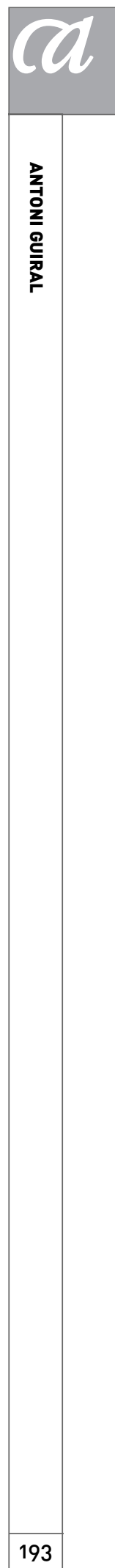


Otra fórmula para albergar aquella inquietud no revolucionaria pero sí abiertamente progresista de la sociedad y de la historieta la encontramos en El Jueves (1977), semanario que, a diferencia de sus precedentes satíricos en la transición, utilizará de forma más habitual la historieta. Herederos directos del espíritu que habitaba el Pulgarcito que volvió a los quioscos en 1947, los responsables de EI Jueves alternan su vocación crítica hacia la actualidad sociopolítica española transmutada en chistes gráficos, textos y montajes fotográficos, con la creación y asentamiento de series de cómics con personajes fijos. Se trata de historietas de una 0 dos páginas protagonizadas por criaturas que responden a la sociología del momento, que revisan no la coyuntura instantánea sino la cotidianeidad del día a día, mostrando las tendencias, frustraciones y anhelos de la gente de la calle. Instaurados en un humor ahora más libre que el de Pulgarcito, pero igualmente sarcástico,

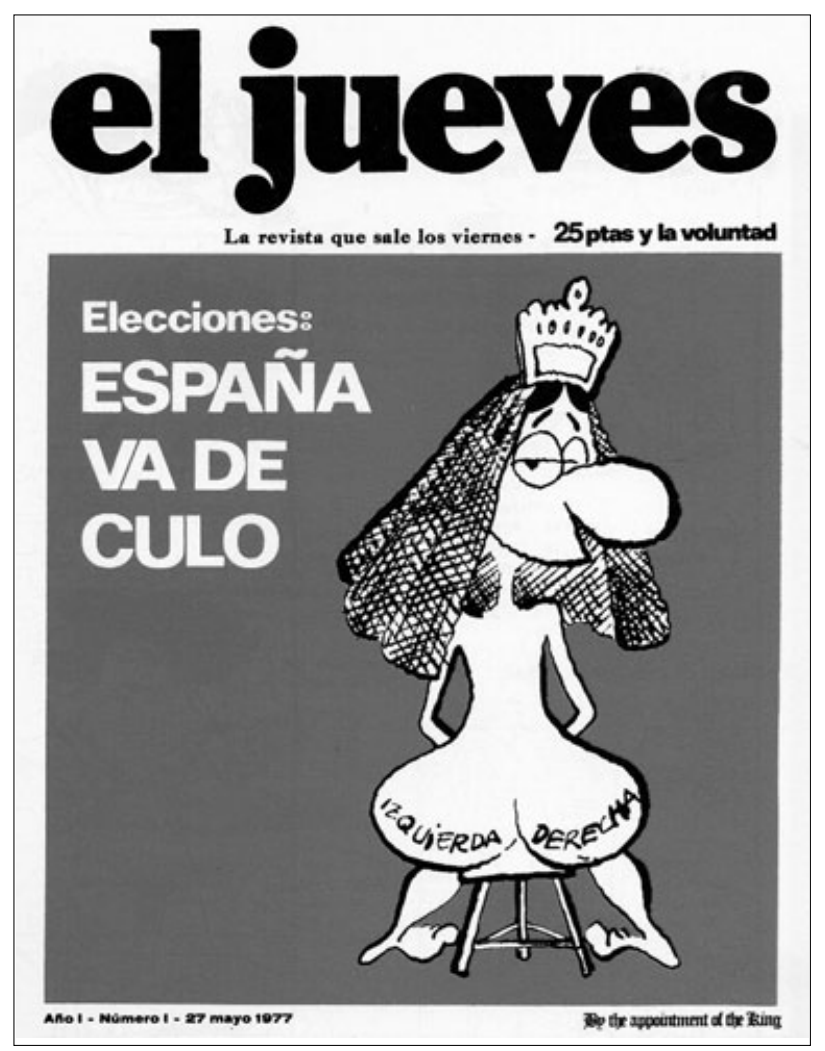

Imagen 7. José Luis Martín es el autor del dibujo de la portada del $n^{\circ} 1$ de El Jueves (1977), semanario satírico de vocación progresista que alberga series de historietas con personajes que retratan la realidad social y política española. los historietistas de El Jueves confeccionarán un retrato social muy crítico de la España del momento con sus rockers, anarquistas, sexólogos, fascistas, exhibicionistas, reivindicadoras, pueblerinos, políticos, militares, chorizos, oficinistas e incluso deidades, aportando también visiones surrealistas y costumbristas de nuestro paisanaje, firmadas por autores como Vaquer, T. P. Bigart, Azagra, Óscar, Kim, Fer, Trallero d'A, Andreu Martín, Mariel, Romeu, Ivà, J osé Luis Martín, Tha, Ventura y Nieto, Manel o Alfonso López.

\section{EN EL PRINCIPIO FUE 'TOTEM'}

Coincidiendo con las primeras elecciones parlamentarias del retorno democrático, y poco antes de que la Constitución iniciase la regularización de la Ley de Propiedad Intelectual y se estableciese el fin definitivo de la censura, la industria de la historieta española acogerá una revista que marcará las pautas para la comercialización definitiva del cómic de autor. Es por entonces cuando tácitamente divorciamos la palabra "tebeo" de "cómic". Ya hacía años que a nivel teórico "tebeo" se identificaba con productos infantiles 0 , como mucho, juveniles, de méritos en ocasiones contrastados pero de contenidos considerados desfasados, erróneamente identificados de forma exclusiva con la más casposa ideología de la etapa franquista de nuestra historia. "Tebeo" era el pasado, "cómic" el hoy y el futuro, y habría que romper definitivamente con lo pretérito para entrar en la modernidad, costase lo que costase. A partir de 1977, pues, es "cómic" lo que identifica a la renovada historieta -término este infravalorado también por entonces-, considerada como medio de comunicación maduro para lectores instruidos y adultos; 0 al menos eso es lo que creímos entonces. Pero la semántica, en este caso, provocó una confusión de la que todavía no hemos salido; en aquel momento lectores, profesionales y aficionados creímos en una división que facilitó olvidos y malas interpretaciones, olvidándonos de que todas las viñetas pertenecen al mismo universo y que la separación entre infantil-juvenil-adulto -0 pasado-presente- no es una escala de valores y calidades, sino de intenciones y contenidos.

Fue un editor italo-argentino, Roberto Rocca, el primero que con su empresa Nueva Frontera instituyó la referencia para esa modernidad del cómic, plasmada en una revista periódica que llevaba el título de Totem (1977). Atrás habían 
quedado definitivamente los cuadernos apaisados, las "novelas gráficas" de bolsillo o los fascículos, incluso la vieja acepción de tebeo o revista infantil-juvenil; Totem identificaba a la nueva revista de cómics por su formato cercano al Din A-4, por su considerable número de páginas y, sobre todo, por la publicación de una historieta para adultos, entendidos estos -0jo- como personas de entre 12 a 30 años: para los más jóvenes quedaban los tebeos de Bruguera, Valenciana y TBO; los mayores, con la desaparición de los cuadernos, habían perdido el tren de la historieta, que solo podían recuperar accediendo a nostálgicas reediciones.
Totem -como muy poco después Blue Jeans (1977) y Bumerang (1978), cabeceras editadas también por Nueva Frontera - fue como un fogonazo de libertad y descubrimientos para el lector español. Con en ocasiones muchos años de retraso, el mensual recuperaba a los principales baluartes de la historieta adulta: en apenas dos o tres años, a toda prisa, recobramos una selección de las mejores viñetas aparecidas en Francia, Italia y Sudamérica, incluyendo el trabajo de creadores como Moebius, Caza, Druillet, Tardi, Lob, Bilal, Schuiten, Lauzier, Forest, Bretecher, Gotlib, Hermann, Crepax, Toppi, Battaglia, Pratt, Manara,
Imagen 8. Totem fue la primera revista que presentó un compendio de la mejor historieta adulta realizada en Europa; portada del $n^{\circ} 1$ (1977), realizada por Moebius.

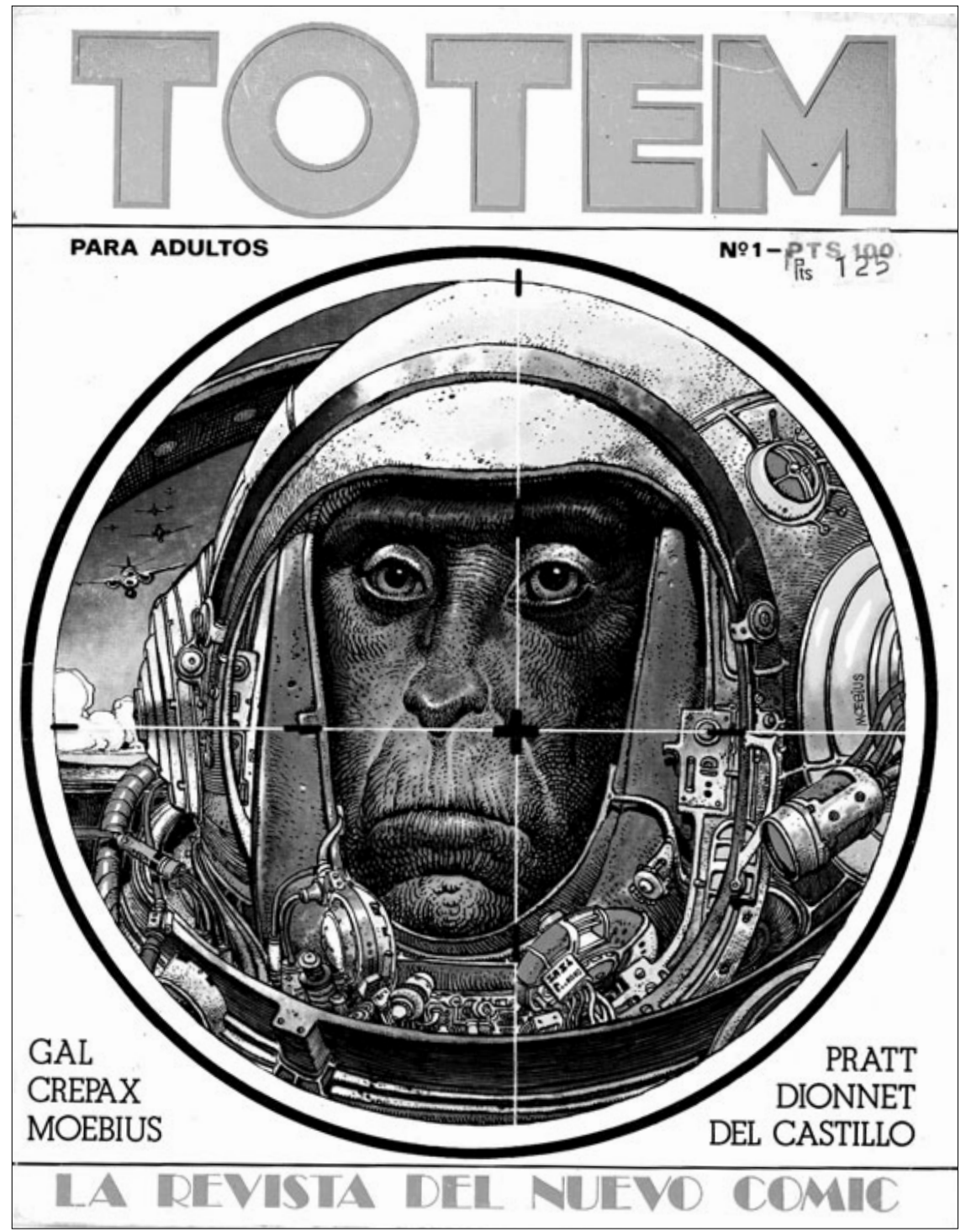

ARBOR CLXXXVII 2EXTRA 2011 183-208 ISSN: 0210-1963

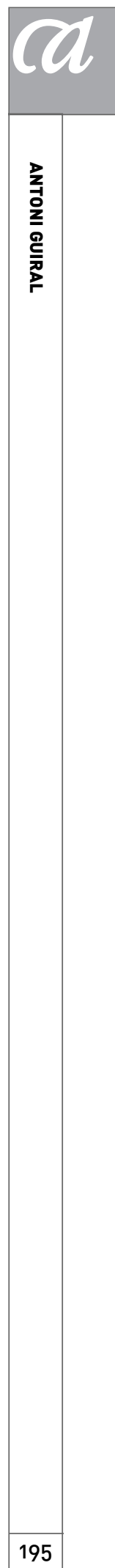


Muñoz, Sampayo, Oesterheld, Breccia, Fontanarrosa 0 Arturo del Castillo. A ellos se añadían obras inéditas o publicadas en Francia e Italia de autores españoles como Luis García, Carlos Giménez, Hernández Palacios, Alfonso Font, Enric Sió, Víctor de la Fuente, José Ortiz, Esteban Maroto o Víctor Mora. En apenas un año Totem, Blue Jeans y Bumerang nos ofrecieron un compendio de más de cuatro lustros de cómics de autor que solo algunos privilegiados habían podido entrever en sus ediciones originales, y que amén de conceder una credibilidad insólita a la "nueva historieta", favorecieron un nuevo modelo de publicación entre otras cosas, no cabe engañarse, porque el éxito comercial sonrió a las propuestas de Nueva Frontera.
El contexto, pues, era perfecto: España estrenaba democracia y libertad; una nueva y amplia generación de posibles lectores, hijos del baby boom, llegaba a edades de inquietudes diversas, la industria española de la historieta no infantil agonizaba, buscando nuevos formatos, y, por fin, el trabajo de encargo de las agencias empezaba a flojear. Este último aspecto es significativo en una doble vertiente: los agentes debían buscar nuevas vías de ingreso y aquellos jóvenes dibujantes formados en las agencias habían adquirido una experiencia notable. Necesidad y ocasión se dieron la mano. Los primeros en reaccionar fueron agentes como J osep Toutain -de Selecciones Ilustradas-y Rafael Martínez - de Norma Agency-. Toutain, que ha

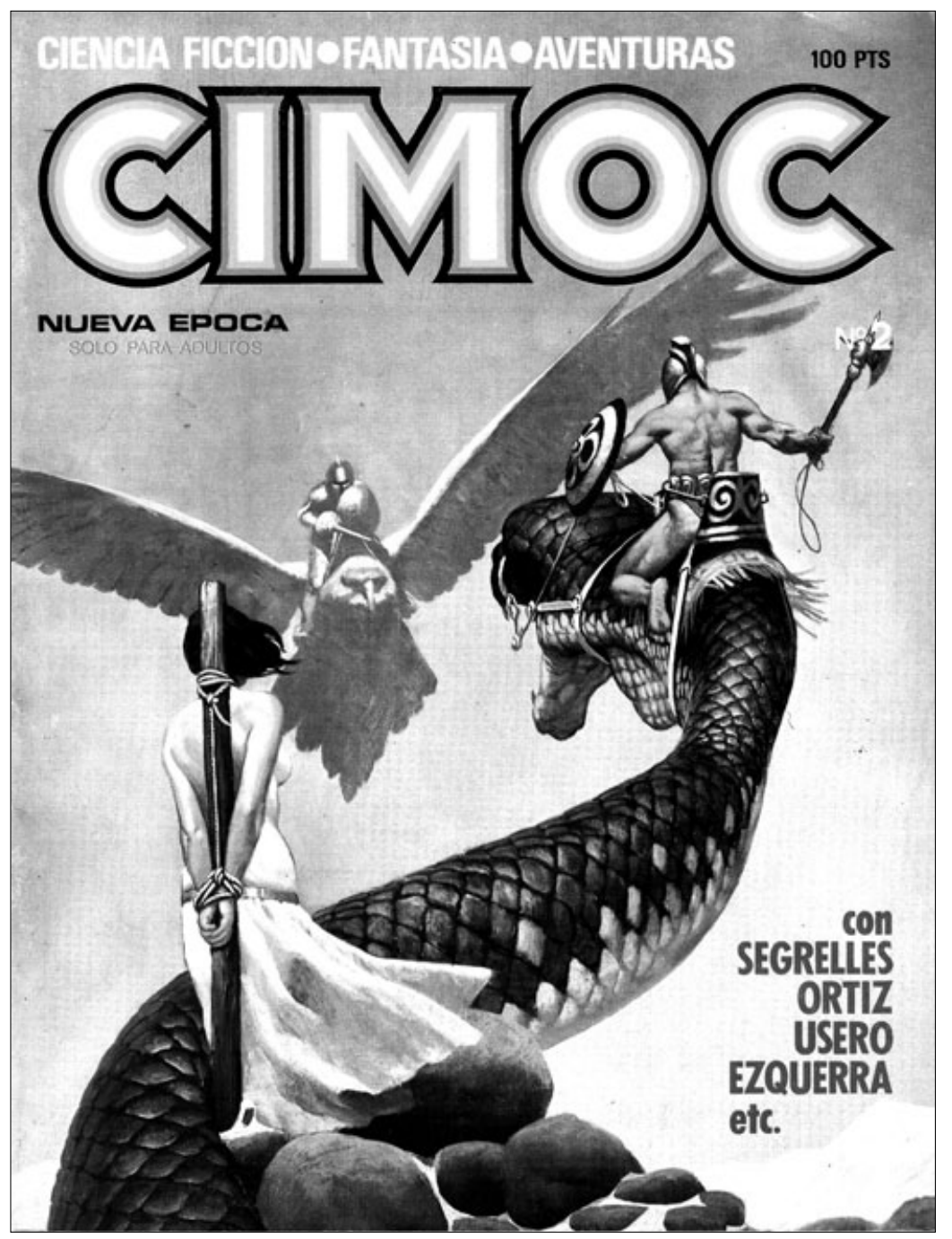

Imagen 9. Cimoc se convirtió en una de las mejores revistas de cómics de aventuras para adultos del boom de la historieta de los años ochenta; portada de Vicente Segrelles para el $n^{o} 2$ (1981). 
había editado algunos libros con el nombre de Toutain Editor, estrenó en 1978 la revista de fantasía y ciencia- ficción 1984, inicialmente ocupada por material de origen 0 coproducción norteamericano; Martínez, que como agente abastecía de material la cabecera Cimoc (1979), acabó por adquirirla, relanzando esta revista como Norma Editorial en 1980 desde el $n-1$.

\section{UN 'BOOM' QUE NO DEJA VER EL FUEGO}

Ya hemos citado a muchos dibujantes españoles con inquietudes autorales que, mientras seguían manteniendo su estatus con historietas por encargo, abordaban material propio con la ambición de controlar su propio trabajo y narrar aquello que más les motivaba. Otros habían encontrado en Francia o Italia a su mercado, atesorando también producciones más libres y personales. De ese poso, del acicate que supuso la posibilidad de publicar en tu propio país tu propia obra, sin renunciar a tus derechos de autor ni a tus originales, de la necesidad de exponer en viñetas aquello que siempre quisiste narrar, de la oportunidad -en algunos casos- de encontrar trabajo y de la esperanza de, renunciando a encargos fijos y seguros, recibir la pecunia necesaria para la supervivencia, nace la historieta autoral española, que vendrá acompañada de lo que, en su momento, se llamó, equivocadamente, boom del cómic.

Así, entre 1979 y 1984 se disparó la locura por el cómic en España. Los quioscos creaban un espacio propio para las decenas de revistas que aparecían y, en ocasiones, desparecían con cierta premura; el aumento de la producción de publicaciones regulares trajo consigo la edición de álbumes, bien recopilaciones de las series previamente aparecidas en revistas, bien con historietas aparecidas directamente en este formato; nacieron nuevas editoriales; para asumir sobre todo álbumes y libros de historieta, se intensificó la aparición de librerías especializadas en toda España; radios, televisión y prensa escrita acudieron a la llamada de la historieta de autor con fruición; aparecieron nuevas revistas teóricas y, sobre todo, muchos fanzines, publicaciones de aficionados en las que librar las primeras batallas artísticas; nacieron jornadas y salones del cómic por todo el Estado, casi siempre apoyados por las instituciones públicas; esas mismas instituciones vieron en el cómic motivo de afección política traducible en votos, y apoyaron también publicaciones regulares; aparecieron escuelas destinadas a la pedagogía de la historieta; incluso apareció una historia de los cómics en fascículos -formato de moda en los quioscos-, financiada por Toutain Editor. Una locura que intensificó un cierto espejismo traducido en el citado boom del cómic, un boom que en efecto permitió un mayor desarrollo de la industria y unos incentivos en ventas que, en algunos casos -aunque sin llegar al extremo de ciertos cuadernillos de los años cuarenta o cincuenta- se tradujo en decenas de miles de ejemplares. Pero para mantener viva y activa una industria de estas características hace falta algo más que un fogonazo coyuntural.

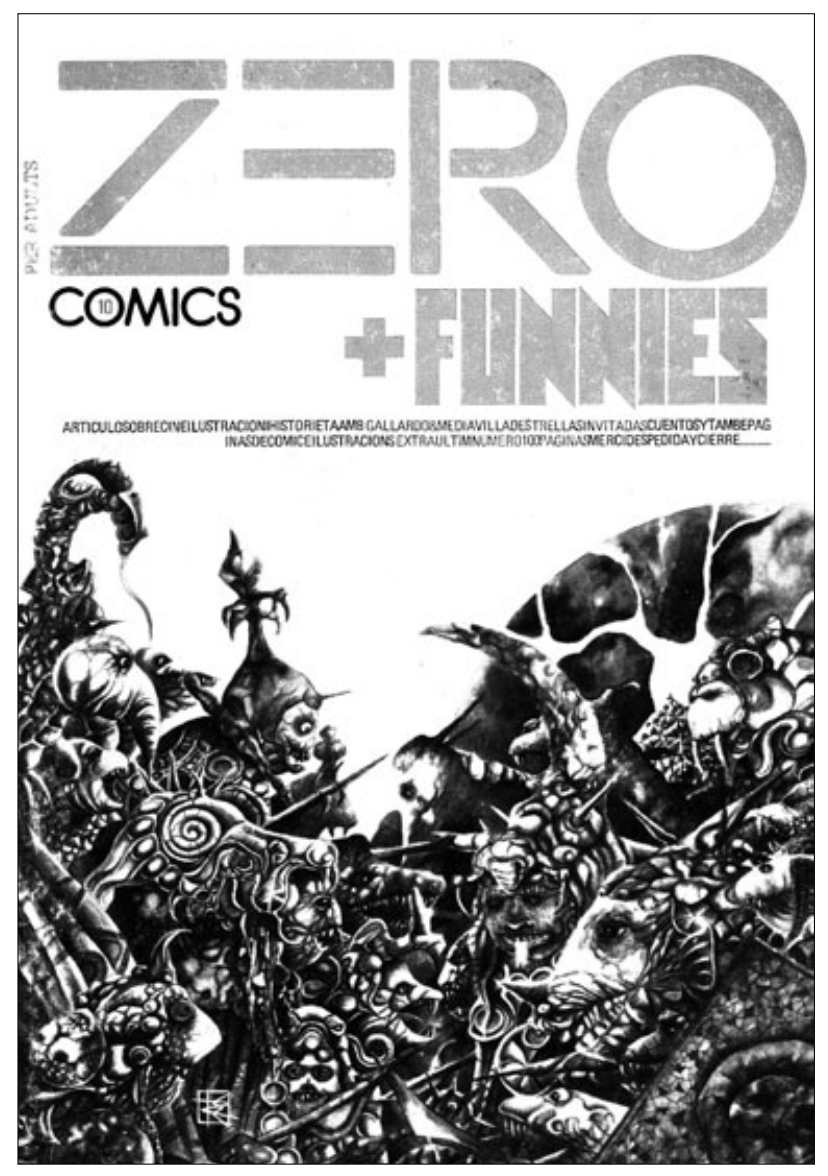

Imagen 10. Entre los muchos fanzines aparecidos en España, destacó Zero Cómics, publicación de la que surgieron muchos de los jóvenes profesionales de los años ochenta; portada del $n^{\circ} 10$ (1984), realizada por Ricard Castells.

ARBOR CLXXXVII 2EXTRA 2011 183-208 ISSN: 0210-1963

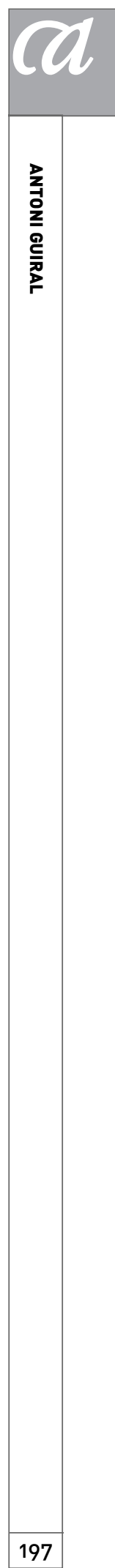


Toutain Editor, principalmente con las cabeceras 1984 (1979, reconvertida a Zona 84 en 1984), Creepy (1979 y 1990 en una segunda época) y Comix Internacional (1980) y Norma Editorial, con Cimoc y Cairo (1981), compartieron pronto espacio en esos quioscos con editoriales recién nacidas como La Cúpula, que publicó El Víbora en 1979, marcando, cada una a su manera y con temáticas y tratamientos distintos, los contenidos de aquellas revistas. Las publicaciones de Toutain Editor y de Norma Editorial alternaban la publicación de material reciente 0 histórico producido en EE UU, Argentina, Francia, Bélgica e Italia, sobre todo, con una ingente cantidad de series de autoría autóctona producidas por estas empresas, amén de insertar en las páginas de sus cabeceras una destacable dedicación a la literatura sobre los cómics, traducida básicamente en artículos informativos sobre autores y/o series y en varias secciones de actualidad. 1984, Creepy y Cimoc concentraron su atención en una historieta más estandarizada, en el sentido de aportar versiones renovadores de géneros populares como la fantasía, la ciencia-ficción, el terror o las aventuras. Había siempre en aquellas series un trazo evidente de la calidad gráfica de unos profesionales madurados en encargos ajenos, grafismos realistas pero de tintes personales, con resoluciones técnicas propias y estilos perfectamente identificables, que servían narraciones ambiciosas en ocasiones, más estereotipadas en otras, con cierta vocación social y política en algunos casos. Fue el momento de firmas como las de Carlos Giménez, Manfred Sommer, Leopoldo Sánchez, Jordi Bernet, Vicente Segrelles, Fernando Fernández, Luis García, Alfonso Font, Auraleón, Josep Maria Beà, José Ortiz, Rubén Pellejero, Luis Bermejo, Pepe González o Esteban Maroto, dibujantes de dos generaciones que se habían forjado, sobre todo, en las agencias; también de algunos autores que como Víctor M ora, Alfonso Font o Víctor de la Fuente se habían exilado profesionalmente hablando, y pronto aparecieron con obra propia excepcionales dibujantes argentinos establecidos en España, como Horacio Altuna o Juan Giménez. A partir de 1981, sobre todo en las publicaciones de Toutain, llegó la nueva hornada de historietistas jóvenes, con estilos muy definidos y ambiciones perfectamente establecidas, como Rafa Negrete, Pedro Espinosa, Josep María Beroy, Pasqual Ferry, Miguelanxo Prado, Das Pastoras, M ike Ratera o Fernando de Felipe.

Comix Internacional y Cairo, en cambio, se convirtieron de alguna manera en las cabeceras "de prestigio" de
Toutain y Norma, respectivamente. La primera, con una complementaria dedicación a la ilustración como indica su título, apostó por obras clásicas y contemporáneas de algunos de los mejores autores norteamericanos -Will Eisner, Milton Caniff, Alex Toth-y sudamericanos -Alberto Breccia, Carlos Trillo, H. G. Oesterheld, Mandrafina- de todos los tiempos, así como por obras originales de creadores españoles inclasificables en principio en los géneros que trataban el resto de cabeceras -Carlos Giménez, Miguelanxo Prado, Das Pastoras-, pero sobre todo ambiciosas en sus planteamientos estéticos y narrativos. Cairo, por su parte, buscó diferenciarse en el mercado con el epígrafe "el neotebeo", atento a algunas de las nuevas líneas estéticas de la historieta contemporánea, como la "línea clara" franco-belga marcada por Hergé pero desarrollada y

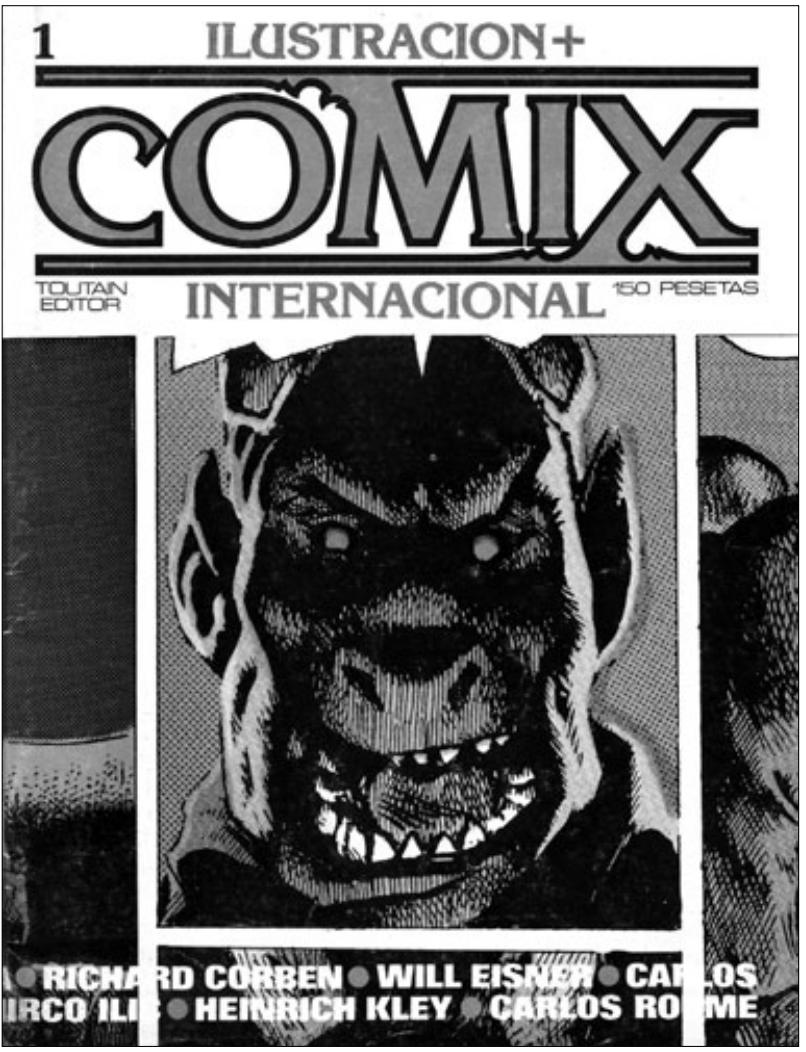

Imagen 11. Montaje realizado a partir de imágenes de Richard Corben para la portada del $n^{\circ} 1$ de Comix Internacional (1980), revista que agrupó a algunos de los más destacados historietistas europeos y

americanos de los años ochenta. 
renovada por E. P. Jacobs, Floch, Ted Benoit, Yves Chaland o Tardi, todos ellos presentes en esta cabecera, material de primera línea completado, en sus aportaciones foráneas, por el italiano Vittorio Giardino.

En lo que respecta a material nacional, siguió la directriz de buscar autores de trazos personales e historietas que navegaban entre el reflejo cotidiano de la modernidad, la relectura de los géneros y un tratamiento sutil, irónico e incluso surrealista del humor, con nombres como Daniel Torres, Mique Beltrán, Pere J oan, M ontesol, Miguel Calatayud, Sento, Mariscal, Micharmut, Tha, TP, Bigart, Ramón de España, Ignacio Molina, Roger, Cifré o Gallardo, amén de dedicar espacio a reivindicar los clásicos de nuestro tebeo, con especial mención a Coll, que publicó varias historietas nuevas en Cairo.

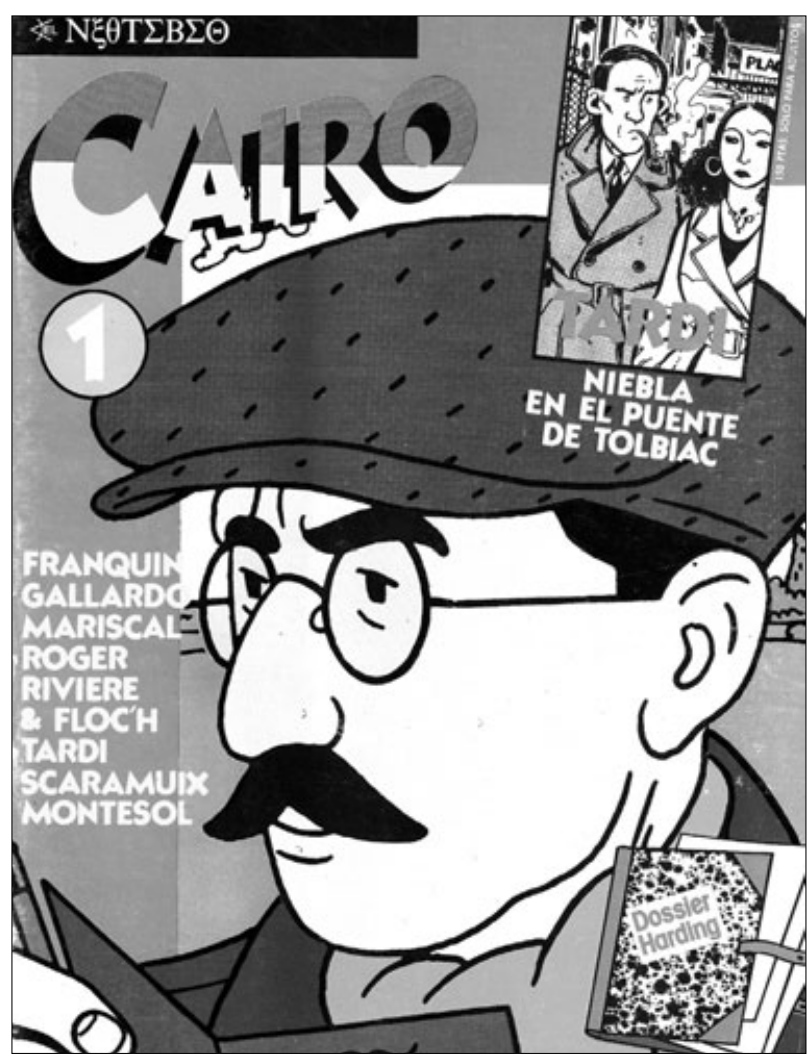

Imagen 12. Cairo ejemplificó la fuerza estética de la "línea clara", una tendencia franco-belga seguida por autores de todo el mundo; montaje con dibujos de Floc'h y de Jacques Tardi para la portada del $n^{o}{ }_{1}(1981)$.

\section{UNA VÍBORA EN JUEVES}

El Vibora, en cambio, se alejó voluntariamente de todos estos parámetros, concentrándose en seguir las premisas del comix underground, pero actualizando sus contenidos y adaptándolos a la idiosincrasia del país. Junto a una excelente selección de material norteamericano -Bill Griffith, Robert Crumb o Spain Rodríguez-, francés -Pétillon o Martin Veyron- e italiano -Pazienza, Carpitieri, Mattioli o Liberatore- de historietas contraculturales, armonizó sus contenidos con las aportaciones de algunos creadores de la "vieja guardia" del comix español, como Nazario, Max, Pons, Martí, Marsical, Gallardo, Mediavilla, Roger 0 Pàmies, abriendo sus páginas a jóvenes creadores como Carulla, Boldú, Laura, Miguel Ángel Martín, Galiano, Rafa Fonteriz o Jaime Martín. A su manera, El Vibora -junto sobre todo a El Jueves-, quedó como uno de los pocos baluartes de una historieta social, punzante e inconformista, manteniendo un valioso equilibrio entre el tratamiento más popular del medio y la obertura a ciertas vanguardias estéticas, lo que la convirtió en una de las cabeceras más vendidas de los años ochenta. Por su parte, Producciones Editoriales, editora de un ya desaparecido Star, intentó reciclar su atención al comix underground hacia una historieta renovadora pero más atenta al costumbrismo y a la sátira con la revista Bésame mucho (1980), en la que junto a obras de autores europeos tan reconocidos como Lauzier, Giardino o Pétillon incluyó aportaciones muy meritorias de creadores hispanos como Manel Gimeno, Sento, Scaramuix o Ramón de España y M ontesol, que con la historia La noche de siempre (1981) aportaron un costumbrismo revitalizador y contemporáneo que precedió a una tendencia continuada posteriormente por otros autores españoles.

Entre 1982 y 1984 se multiplicó en los quioscos la oferta de revistas; el negocio funcionaba y había que explotar la coyuntura. M ientras Norma añadía a su fondo títulos como A tope (1982) y La Cúpula hacía lo propio con Makoki (1982), Ediciones El Jueves lanzaba Titanic (1983) y Toutain Thriller (1984), revistas que, excepto la primera, dedicada al humor erótico, no pasaron del año y medio; Nueva Frontera, por su parte, seguía acaparando espacio con cabeceras como Vértigo (1982), Totem Calibre 38 (1982) 0 Totem, aventuras y viajes (1983), buscando revalidar el éxito de Totem sin conseguirlo, aunque sí encontró una cierta relevancia en otro de sus títulos, Metal Hurlant (1981), 
versión española de una cabecera francesa básica en la historia del cómic para adultos, que a partir de su no 4 pasó a ser editada por Eurocomic.

En realidad, y a excepción de El Vibora y El Jueves, solo había dos fórmulas hábiles para sobrevivir en aquel maremágnum de publicaciones. 0 , como Nueva Frontera y otras editoriales, concentrarse en la publicación de material foráneo de calidad contrastada, con lo que los costos editoriales eran mínimos, 0, como hicieron Toutain y Norma, basarse en su negocio de la agencia para asegurar sus cabeceras. Lo cierto es que, aunque el negocio funcionase, la producción de material original para las revistas por parte de los editores era costosa. Por otro lado, y aunque los precios por página eran dignos en muchos casos, los autores difícilmente podían mantenerse económicamente hablando entregando ocho páginas al mes. La supervivencia, tanto por parte de la editorial como del creador, pasaba por una operación doble. Por un lado, asegurar la posterior recopilación de una serie prepublicada en revista en un álbum 0 libro, lo que significaba otra forma de comercializar el producto y sacarle rédito -lo que no siempre ocurría, bien porque no se editaba el álbum, bien por sus magras ventas-; por otro, el editor-agente tenía la ventaja de que al asegurarse que los autores le cedían los derechos de representación de su material creado para la editorial, podía vender esas series a otras editoriales europeas 0 americanas. A medida que pasaba el tiempo, el editor-agente, que ya tenía sus contactos establecidos, era consciente de la importancia de esas transacciones para asegurar la rentabilidad de su primera inversión, por lo que a la hora de producir nuevo material cada vez más se movía por los intereses o consejos de los editores foráneos. De alguna manera, se repetía la interacción entre cliente y vendedor de las agencias, entre demanda y oferta, solo que esta vez con historietas de autor cuya propiedad era de los creadores.

\section{AutOgesión}

Por considerar que su colaboración no estaba suficientemente bien atendida en todos los sentidos, y por la sana ambición de controlar hasta el último aspecto de sus producciones, algunos autores decidieron mancomunar sus esfuerzos pecuniarios y creativos y constituir sus propias editoriales. Así, aunque la revista Rambla nació con el sello de Distrinovel en 1982 - con la condición de una dirección ejercida por los propios creadores-, muy pronto quedó en manos de dos de ellos, pasando a ser publicada por García \& Beà Editores. Rambla era un proyecto muy ambicioso. A diferencia del resto de cabeceras del momento, la intención era la de publicar única y exclusivamente material original realizado por historietistas españoles, con entera libertad por su parte y manteniendo el control creativo absoluto de su obra. El primer consejo de redacción estuvo formado por autores como J osep María Beà, Alfonso Font, Luis García y Adolfo Usero, todos ellos colaboradores de Rambla junto, al principio, compañeros de la talla artística de Carlos Giménez, Ventura y Nieto, Víctor Mora, Kim, Enric Sió, Alfonso López, Tha, Marika o El Cubri. La filosofía de Rambla no respondía a un ideario común o a un tratamiento de género concreto; primaba el talento del autor para concebir obras personales e intransferibles que debían responder únicamente

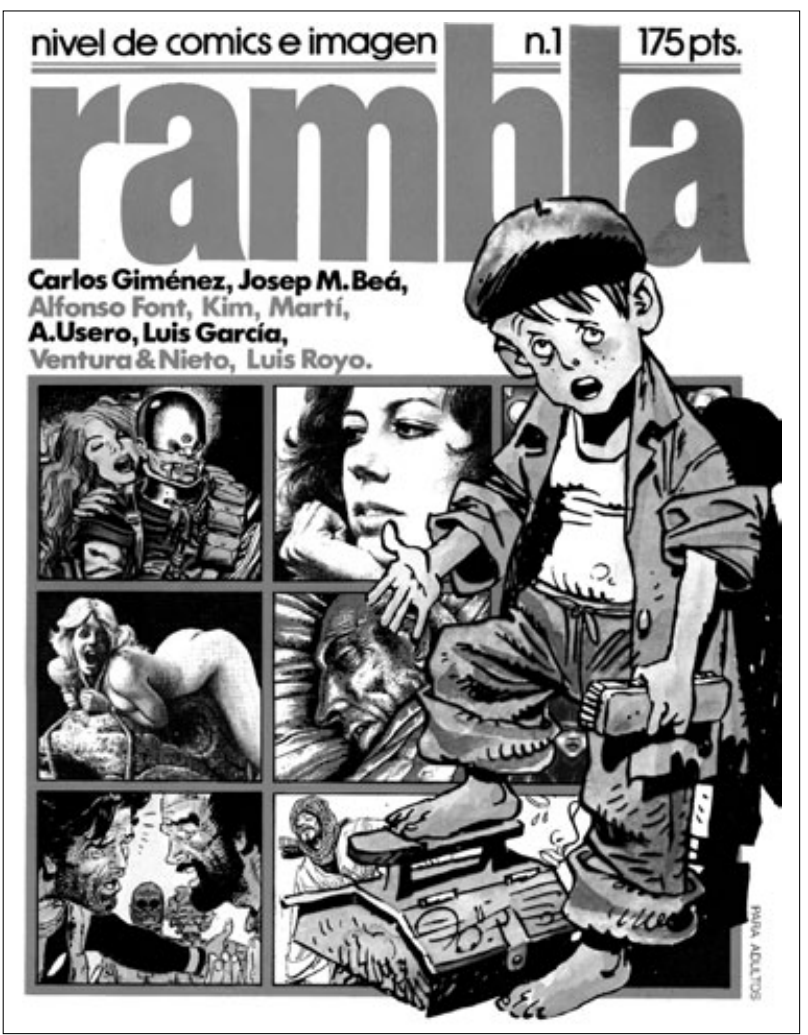

Imagen 13. Rambla, autogestionada por un grupo de autores de cómic, apostó por la historieta española desde su primer número (1982); montaje con imágenes de Beà, Luis García, Ventura y Nieto, Kim, Alfonso Font, Adolfo Usero y Carlos Giménez. 
a sus ambiciones artísticas. Solo así se entiende que en una misma publicación -salvo quizá en Comix Internacionalpudiéramos encontrar historietas de crítica social junto a cómics de aventuras, mezclados con narraciones surrealistas, piezas humorísticas, obras históricas, experimentos narrativos, argumentos policíacos o relatos políticos, y todo ello asumido por estéticas muy diversas que iban desde un tratamiento figurativo hasta estilos pictóricos casi impresionistas. Luis García y Josep María Beà se hicieron cargo de la edición de Rambla con muchos esfuerzos - compaginar la gestión con su obra no era fácil-, teniendo pronto que renunciar a la exclusividad de colaboraciones específicas de autores del país para integrar material extranjero. Con todo, y en sus últimos números editada solo por García, Rambla sobrevivió hasta 1986, llegando incluso a proponer otras cabeceras alternativas, como Rambla Quincenal, Rambla Rock 0 Rampa-Rambla.

Algo parecido, pero de forma más efímera y en otras circunstancias, ocurrió con Ediciones Metropol, forjada por un grupo de los autores más destacados de las revistas de Toutain y Norma y dirigida por el guionista Mariano Hispano y el dibujante Leopoldo Sánchez. Su primer proyecto, concentrado en la revista Metropol (1983), era también muy vehemente; no solo utilizarían material original de autores españoles, sino que concentrarían argumentos y textos alrededor de una ciudad ficticia, Metropol, de forma que, de alguna manera, todas las historietas estaban interrelacionadas entre sí, todas ellas transcurrían en un entorno concreto que marcaba el devenir de sus personajes. Hispano y Sánchez, junto a Antonio Segura, Jordi Bernet, Manfred Sommer, José Ortiz, Bartolomé Seguí, Saladrigas, Génies, Leopoldo Ortiz, Andreu Martín, Enrique S. Abulí, Carlos Echevarría, J osé Aguilar, J osep María Cardona y Mariel dotaron a esta iniciativa de una coherencia admirable y sorprendente, con argumentos que cruzaban la aventura con el policíaco o la crítica social con el humor. Ediciones M etropol, además, publicó también dos números de la revista de aventuras Mocambo (1983) y cuatro de KO Comics (1984), un verdadero reto este último que Norma Editorial se tomó como una afrenta, ya que Sommer, Segura, Ortiz y Sánchez trasladaron a sus personajes fetiche -Frank Cappa, Hombre y Bogey, publicados hasta entonces en la revista Cimoc- a su propia publicación, amén de contratar una novela gráfica de Will Eisner para publicarla por entregas, haciendo suyo así un autor y una línea de trabajo que hasta entonces había sido publicada en España por Toutain. El reto no salió bien;

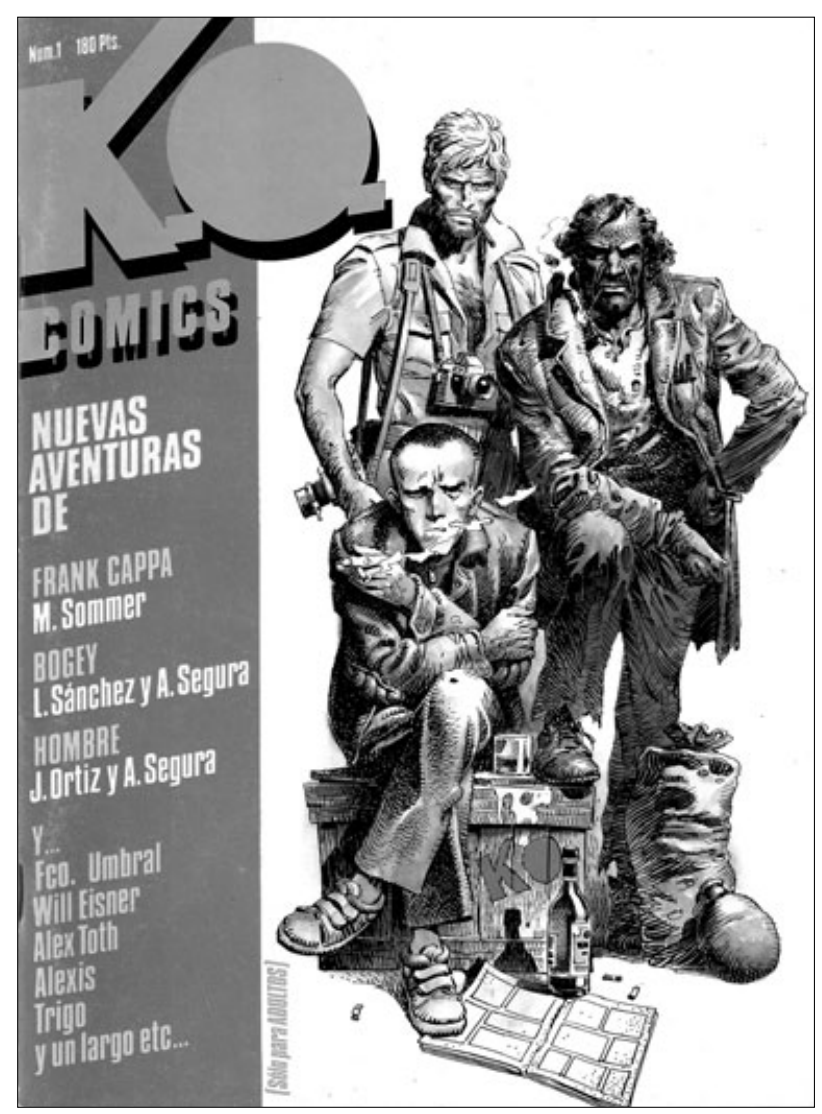

Imagen 14. La portada del primer número de KO Comics (1984) presenta a tres de los más populares personajes del cómic de aventuras de aquel momento: Frank Cappa, Hombre y Bogey. Portada ilustrada al alimón por Manfred Sommer, José Ortiz y Leopoldo Sánchez.

Ediciones Metropol cerró todas sus publicaciones un año después de su nacimiento, en 1984, a pesar de la evidente calidad de sus propuestas. Algunas de la series de Metropol y de KO Comics volvieron a Toutain Editor y Norma Editorial, pero aquella experiencia, lúcida en su origen pero ingrata por un final que sus gestores refieren a oscuros intereses comerciales, marcó el ánimo de sus protagonistas.

\section{OtRAS LENGUAS, OtRAS FINANCIACIONES}

La proliferación de publicaciones periódicas de esta etapa llega hasta ámbitos lingüísticos como el catalán y el euskera. En 1982, Saco Roto, formada en su base por 
ex miembros del equipo Butifarra, edita la revista en formato periódico Cul de Sac en lengua catalana, que incluye una visión poco cómoda, muy crítica, de la realidad catalana del momento, complementada con historietas de géneros como la aventura o el policíaco. El mismo año, Habe, organismo autónomo del Gobierno Vasco para la alfabetización en euskera, publica la cabecera de cómics Habeko Mik, que abre sus páginas a guionistas y dibujantes vascos que abordan todo tipo de tratamientos genéricos. Dos años después, será el Ayuntamiento de Madrid quien -en español, claro- financie una revista de cómics que, en realidad, nada tiene que ver con el resto de publicaciones de historietas del momento. La filosofía de Madriz, dirigida por el guionista y teórico Felipe Hernández Cava -miembro de El Cubri-, apuesta por la libertad absoluta de los autores, renunciando a cualquier atisbo de comercialidad en sus propuestas tanto estéticas como narrativas. Este excelente planteamiento -idóneo para una revista de carácter público por abrir los ojos a otra formas de entender el mediopermite a jóvenes y no tan jóvenes profesionales de la historieta emprender viajes a mundos experimentales que dotan de personalidad propia a la revista, al tiempo que convierte a ilustradores, pintores y otros artistas plásticos en historietistas que, ajenos a directrices previas, reinterpretan las esencia del medio a su manera. Por otro lado, Madriz fue también hábitat de muchos nuevos y jóvenes historietistas con propuestas renovadores que, de no ser por esta publicación, no habrían encontrado hueco en el que publicar. Entre sus principales colaboradores destacaremos a: Carlos Giménez, Ceesepe, El Cubri, LPO, Raúl, OPS, Fernando Vicente, Federico del Barrio, Arranz, Micharmut, Javier Olivares, Gallardo, Cifré o J. Gras.

\section{EL EXCESO MATA EL HAMBRE}

Aunque el mercado de revistas para adultos continuó relativamente vivo y activo hasta 1992, lo cierto es que en 1985, y salvo contadas excepciones, daba síntomas de hallarse en vías de agotamiento. A propuestas interesantes pero muy breves -Complot! (Ediciones Complot, 1985), HDiosO (Ediciones El Jueves, 1986), Luca Torelli es Torpedo (Makoki, 1991)-, se unían otras también efímeras que intentaban rescatar a fans de la historieta clásica -Gran Aventurero (Ediciones B, 1989) o Top Comics (Ediciones B, 1994)-, apostar por un cómic de calidad en una revista de cultura general -Co \& Co (Ediciones B, 1993) ${ }^{4}-$, o recuperar la "vieja" fórmula de la revista de cómics para adultos con series de procedencia y tono muy distintos -Viñetas (Ediciones Glénat, 1994)5-. También hubo un hueco para iniciativas peculiares, como Rumbo Sur (1985), cabecera de ocho números editada por la Caja de Ahorros y M onte de Piedad de Sevilla, un producto de calidad técnica - papel, impresión- inhabitual entre las revistas de cómics, donde publicaron firmas como las de Jan, Antonio Hernández Palacios o Alfonso Font. En 1986 aparece la penúltima propuesta en forma de revista de Toutain Editor, Totem el Cómic, que es, como indica su título, una nueva etapa de la ya clásica Totem, pero esta vez más concentrada en una historieta entre aventurera y erótica, y en 1989 Makoki pone a la venta una nueva versión de la revista que lleva el título de la editorial y del personaje, Makoki, uno de los últimos ejemplos -si no el último- de situar en el mercado una publicación de cómics alternativos y provocadores, que junto a un largo elenco de historietistas jóvenes incluyó material de veteranos como M anuel Vázquez, Jordi Bernet, Enrique S. Abulí o J uan García Iranzo.

En 1995, de todas las cabeceras mencionadas hasta ahora solo quedaban activas EI Jueves, TMEO y EI Vibora; Cimoc, Top Comics y Viñetas cerraron aquel mismo año, cuando además muchas de las editoriales citadas ya habían desaparecido. De hecho, la crisis que rondaba a este mercado hacia mediados de los años ochenta ya era una cruda realidad en 1990, cuando la fórmula editorial de este tipo de revista estaba absolutamente agotada. Un fenómeno que no fue exclusivo del mercado español; Francia e Italia sobre todo -quien más apuesta, más pierde- se resintieron, y muchas de sus cabeceras -incluidas al gunas históricasdesaparecieron. Pero la historieta se había asentado en sociedades como la francesa y la italiana como una herramienta cultural más, por lo que allí supieron y pudieron asumir la crisis y reinventarse para continuar generando mercado. No fue así en nuestro país, que de nuevo volvió a evidenciar sus puntos débiles, tanto sociales como industriales, en este sentido: la historieta seguía siendo la pariente pobre de los medios de comunicación; no se había consolidado social ni culturalmente hablando, la escuela la había rechazado o ignorado, las nuevas generaciones la desconocían por no existir productos industriales pensados para niños, y ni "tebeo" ni "historieta" ni "cómic" significaban mucho más para la mayoría de la gente de la calle que la última aventura de Mortadelo y Filemón. 
Ahora, permítaseme hacer una breve valoración de las posibles razones del fracaso de las publicaciones periódicas de cómics para adultos y de su incidencia en la profesión.

\section{BUSCANDO RAZONES}

Ya dijimos hace bastantes líneas que el fenómeno del boom de la historieta para adultos en España afectaba, en realidad, a "jóvenes-adultos" de 12 a 30 años. En realidad, los editores fueron descubriendo la edad de sus lectores con el tiempo, y a partir de ese momento concentraron sus esfuerzos en este segmento generacional. No todas las obras publicadas en aquellas revistas iban dirigidas 0 estaban pensadas para jóvenes lectores adultos, pero muchas de ellas, de forma consciente 0 inconsciente, llevaban ese marchamo. Por tanto, cuando aquel lector de 14 años que en 1977 empezó a comprarse Totem llegó a sus 30 años en 1993, se detuvo el reloj; no para él, que seguía con su pareja, piso y coche $-\mathrm{y}$, por tanto, inmerso en otras realidades fuera de la viñeta-, sino para las revistas, incapaces de acompañar a su público en el avance madurativo que debería de suponer la acumulación de años y experiencia. No hubo traspaso generacional, lo que fue aprovechado por otros formatos de edición, que poco a poco fueron desbancando a las revistas "para adultos" de los quioscos y las librerías especializadas. En 1993 los más jóvenes andaban ocupados en el comic-book y en el manga. $Y$ es que tras unos años dando bandazos entre la reproducción en blanco y negro y los cambios de formato, el comic-book norteamericano empezó a asentarse en España en 1983, cuando Comics Forum, filial de Planeta DeAgostini, adquirió los derechos de Marvel Comics e inició unas excelentes ediciones españolas, donde traducción, rotulación, calidad de reproducción y atención al lector fueron un rito común, continuado desde 1984 por Ediciones Zinco con el material de DC Comics. Los jóvenes hallaron "sus" tebeos en aquellos comic-books, hasta que unos años después, tras recibir el impacto del producto en las televisiones, los niños descubrieron en 1992 de la mano de Planeta DeAgostini los manga con Dragon Ball, iniciando así una relación sentimental con la historieta japonesa que pervive muy activa hoy en día.

Por otro lado, el concepto revista empezó a generar muchas dudas cuando los editores, por cuestiones comerciales, regularizaron la recopilación en álbum de algunas de las series de sus revistas. Tampoco es que a este nivel hubiera una política coherente, pero lo cierto es que las consideradas series más comerciales acababan, casi siempre, recogidas en un libro -sobre todo en tapa blanda-, que por entonces llegaba incluso a los quioscos además de a las librerías especializadas. Con el tiempo, muchos lectores, que aparte de sus autores favoritos no encontraban otros alicientes en aquellas revistas periódicas, decidieron esperar a la aparición del álbum. Y es que el efecto catálogo de las cabeceras era cada vez más evidente; catálogo en cuanto a avance de las próximas novedades que iban a ser publicadas como libros - un apartado de la industria que por entonces funcionaba bastante bien-, y también en cuanto a muestrario para las editoriales foráneas de las series españolas que podían contratar. Además, con el tiempo empezó una cierta deserción de creadores; algunos profesionales maduros estaban cansados de batallar con un mercado incierto y consideraban que sus méritos no eran reconocidos ni económica ni artísticamente hablando. Otros volvieron a emigrar, esta vez contactando directamente con los editores franceses e italianos, en busca de ese reconocimiento que solo una industria bien asentada puede aportar. Hubo quienes encontraron trabajo en otras lides relacionadas con la imagen -el diseño o la ilustración-y lo que tenían capacidad apostaron por la historieta humorística buscando la garantía que ofrecía El Jueves.

Hay un aspecto a mi modo de ver básico para entender todo lo expuesto hasta ahora: los guiones. He estado hablando sobre todo de dibujantes -muy pocos guionistas he citado como colaboradores de revistas-, pero conviene remarcar algunos detalles que a veces pasan desapercibidos incluso para los propios profesionales. El guión es la base de una historieta. Sin un buen guión no existe la buena historieta. Históricamente hablando, en España la figura del guionista es como seguir un vía crucis en Semana Santa. Existieron en la época dorada del cuadernillo y de la revista, aunque casi nunca fueron identificados ni reconocidos en los créditos; trabajaron a destajo por unos precios irrisorios, conscientes, en muchos casos, de que su figura no era imprescindible, solo complementaria para que el dibujante tuviera más tiempo para dedicar a sus páginas y producir más. Algo parecido les ocurrió a los pocos guionistas españoles que trabajaron para las agencias. Pero cuando llegó la historieta para adultos pocos de esos profesionales, expertos en lides narrativas por experiencia, 
aparecieron. Apenas algunos procedentes del cuadernillo, como Mariano Hispano o Víctor M ora -más concentrado en sus series para el mercado francés por entonces-, y unos pocos colaboradores de agencias, como Enrique S. Abulí, Andreu Martín, Pérez Navarro, Juanjo Sarto o Carlos Echevarría. La progresiva consolidación de las revistas favoreció la aparición de nuevos profesionales de la escritura, autodidactas -como por otro lado todos los guionistas y dibujantes citados- pero sin experiencia, aunque algunos de ellos tuvieron tiempo sobrado para adquirirla, como Antonio Segura o Josep María Polls, especializados en historietas de género; Jorge Zentner 0 T. P. Bigart, con argumentos menos convencionales 0 tratamientos humorísticos llenos de surrealismo, y Carlos Trillo, uno de los mejores guionistas argentinos de todos los tiempos, que produjo para España diversas series con autores como Horacio Altuna o J ordi Bernet. Hubo un espacio temporal breve para la incorporación de una nueva savia muy bien preparada que, sin embargo, no tuvo tiempo suficiente como para desarrollar todo su potencial, por cuanto llegaron casi al final de esta aventura industrial, como Juan Bas, Narcis Fradera, Lorenzo F. Díaz, José Miguel Pallarés, Antonio M oreno u Óscar Aibar. Y también estuvieron aquellos escritores más especializados en temáticas contraculturales, experimentales o cotidianas, como Mediavilla, Onliyú, Pons, Antonio Altarriba, Ramón de España e Ignacio Molina. Mención especial, a mi juicio, merece el ya citado Felipe Hernández Cava, inclasificable francotirador de nuestra historieta cuya obra es siempre fruto de sus inquietudes personales, que nos ha dejado -y lo sigue haciendoobras de gran mérito literario. Son unos cuantos nombres, sí, pero no los suficientes. $Y$ es que para germinar la madurez de esa historieta "para adultos" se necesitaba tiempo, por un lado, pero también oportunidades para desarrollar y perfeccionar el trabajo. Y salvo excepciones muy contadas, ninguno de estos guionistas vivía de escribir historietas. Es más, aquella figura seguía siendo algo insólita y solo complementaria; muchos dibujantes seguían pensando que los guionistas eran sus ayudantes, no sus compañeros en la autoría de una obra. Y como, con razón, un buen número de esos dibujantes profesionales procedentes de agencia estaban hartos de transcribir en viñetas guiones densos, penosos 0 sencillamente intrascendentes, prefirieron escribir los suyos propios porque, en muchos casos, tenían cosas que decir y sabían cómo hacerlo.

El caso es que desaparecidas las revistas, se cerró también un canal para la formación de autores de cómics. Con las agencias resistiéndose a los cambios habidos en los países productores, que iban reduciendo títulos de forma alarmante, y contando con que muchos de los jóvenes aspirantes a profesional se habían reconocido en el cómic de autor y no querían sucumbir al trabajo de encargo, las cabeceras regulares eran la única escuela que les permitía ir avanzando con paso firme. Pero la escuela se cerró, acabando con una generación nueva o limitándola a otras formas de difusión más peligrosas para alcanzar una maduración eficaz, como la autoedición o la edición no profesional, lo que implica libertad pero también falta de dirección, un trabajo que supuestamente debían de haber realizado los editores o los directores y coordinadores de publicaciones; lamentablemente, durante este espacio de tiempo al que nos referimos, estos tuvieron demasiado trabajo administrativo, por lo que la figura del "editor" como persona con ideas a desarrollar que ayuda a los creadores a confeccionar su trabajo e inventa líneas y colecciones, fue prácticamente inexistente en nuestro mercado. Todo ello nos lleva a que sin prepublicación en revista difícilmente puede financiarse una obra que ha de ser editada directamente en formato de libro, lo que provoca que muchos profesionales deban buscar trabajo en otras lides. Finalmente, y para cerrar el tema de este tipo de revistas y las causas de su desaparición, decir que transmitían algo consustancial a aquel mundillo de la historieta, que es una sensación de universo cerrado, de exceso de "ombliguismo", que los -que nos- permitía reconocernos como grupo estanco, distintos del resto del mundo, pero que también provocaba una imagen maniquea e incierta del medio, lo que sin duda no favoreció a la profesión.

\section{VIÑETAS EN LIBROS}

Hasta la época que nos ocupa, el formato álbum -o libro de cómics- no era demasiado habitual en España, al menos para los autores nacionales. Apenas hacía diez años que de forma más o menos regular aparecían álbumes en cartoné de series franco-belgas; fue precisamente en 1969 cuando una editorial se dispuso a recoger en este formato las aventuras de unos personajes españoles aparecidos previamente en una revista: Bruguera, concretamente, con El sulfato atómico, la primera aventura larga de Mortadelo y Filemón. Antes hubo muy pocos ejemplos de tomos recopilatorios de historieta autóctona, y menos aun de 
obras realizadas directamente para este tipo de edición. Bruguera continuó su política a este nivel en colecciones como Ases del Humor y Alegres Historietas (1970), y luego con Olé! (1971), seguida muy de cerca por Ediciones Doncel, que hizo lo propio con varias series de las aparecidas en su revista Trinca a partir de 1970. Con respecto a material de autores españoles, Ediciones Amaika inicia en 1975 una línea de tomos en tapa blanda con material inédito, con títulos como Simbad el marino -de Chiqui de la Fuente-, El pequeño salvaje -José Ortiz-, La isla del tesoro (1977) -del grupo Premià-3, compuesto por Luis García, Carlos Giménez y Adolfo Usero- u Hom (1977) -otra excelente obra de Carlos Giménez que adapta una novela de Brian W. Aldiss-. En 1978 será la madrileña editorial Ediciones de la Torre la que con su colección Papel Vivo

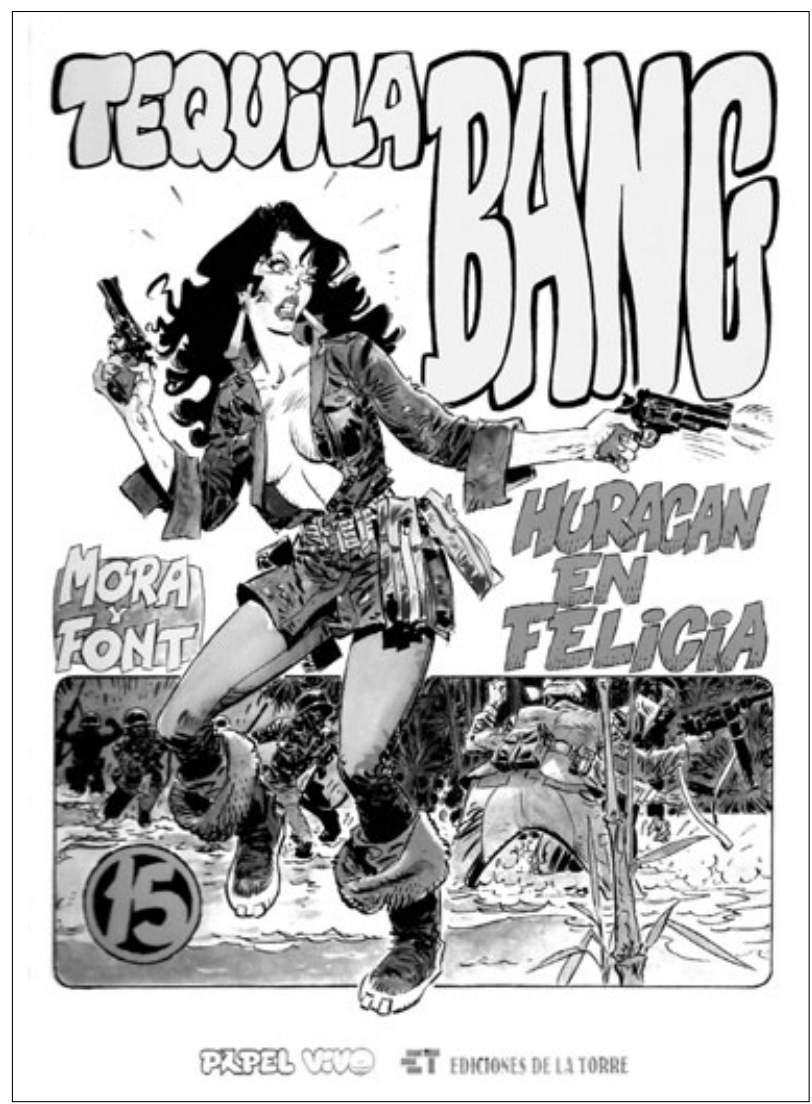

Imagen 15. La colección Papel Vivo de Ediciones de la Torre incluyó títulos de varios autores españoles; portada de Alfonso Font para el $n^{o}{ }_{15}$ (1980), un episodio de Tequila Bang, personaje de Victor Mora $y$ Font. recoja hasta 1997 una soberbia selección de obras, bien prepublicadas en distintas revistas bien originariamente aparecidas en álbum, de creadores de la talla de Carlos Giménez, Alfonso Font, El Cubri, Luis García o Víctor M ora, entre otros.

A partir de 1979, las editoriales con revista propia, como Nueva Frontera, Toutain Editor, Norma Editorial, Ediciones El J ueves, Eurocomic o Ediciones Glénat, ponen a la venta diversas colecciones en las que alternarán la recopilación de series prepublicadas en sus cabeceras con material inédito. También es en 1979 cuando se pone en marcha la editorial vasca Ikusager, un ejemplo de excelente diseño y cuidada producción de álbumes, cuya política se concentra en la confección de obras específicas para sus colecciones,

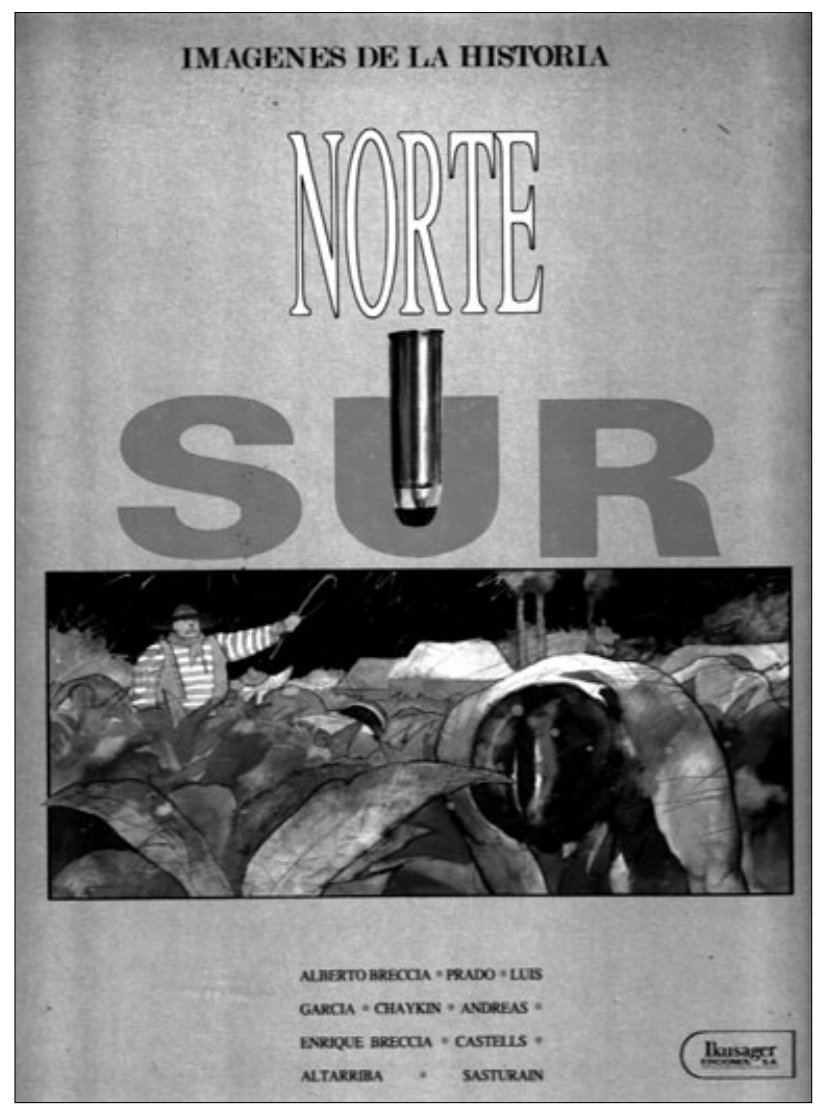

Imagen 16. Ikusager produjo varios álbumes dedicados a temas sociales, como Norte-Sur (1989), que contó con la colaboración de excelente creadores españoles, europeos y norte y sudamericanos; la ilustración de la portada es obra de Enrique Breccia. 
para lo que contactará con algunos de los mejores autores hispanoamericanos del momento, como Antonio Hernández Palacios, Felipe Hernández Cava, Enrique Breccia, Federico del Barrio, Víctor de la Fuente, Luis García, Miguelanxo Prado, Ricard Castells, Carlos Nine, Carlos Trillo o Mandrafina. Entre 1981 y 1990 será la Editorial Complot, dirigida por Joan Navarro, experto en cómics y editor, quien en su colección Misión Imposible recupere series de Cairo, Cimoc y El Vibora, básicamente, con autores como Daniel Torres, Gallardo, Mique Beltrán, Pere Joan, Micharmut, Max, Mariscal, Tha, Montesol, Pasqual Ferry, Garcíes, Sento o Miguel Calatayud. Otra pequeña empresa, Editorial Arrebato, inaugura en 1983 un nuevo formato más pequeño $(17 \times 24 \mathrm{~cm})$ y muy cuidado, donde en álbumes de cartoné publica obras originales para su colección de, entre otros, miembros de la escuela valenciana como Micharmut, Sento Miguel Calatayud, amén de Max, Javier de Juan o Gary Panter. En 1992, la sociedad estatal Quinto Centenario y Planeta DeAgostini, con motivo, evidentemente, del quinto centenario de la "conquista" de América, ponen a la venta la colección Relatos del Nuevo Mundo, una ambiciosa colección que integra obras inéditas de creadores americanos -Alberto Breccia, Enrique Breccia, Carlos Nine, M uñoz, Jorge Zentner-, italianos -Attilio M icheluzzi, Sergio Toppi, Lorenzo Mattoti-, franceses -Paul Gillon-y españoles - Max, Antonio Navarro, Andreu Martín, Juanjo Sarto, Miguel Ángel Nieto, Hernández Palacios, José Ortiz, Luis Bermejo, Calatayud, Alfonso Font o Rubén Pellejero-.

\section{FORMATOS IMPORTADOS}

El formato comic-book -más manejable, más económico-, se convierte en el rey del mercado a principios de los años noventa, sustituyendo en el interés de los lectores $-y$ de los autores españoles-, a la revista periódica. Esta fórmula, que tiene algún precedente en 1989, cuando Norma Editorial publica la miniserie de seis números Opium, realizada por Daniel Torres con la colaboración de Factoría Acme, Incha, Paco Hernández y Ramón Marcos, empieza a establecerse en 1993 con la aparición de Camaleón Ediciones. Pequeña editorial constituida por Álex Samaranch, Juan Carlos Gómez y José Ángel Cano, es la primera en apercibirse que este formato -muy popular en España gracias a los títulos superheroicos-, es idóneo para la producción de nuevas obras de jóvenes autores del país. Su primer título como comic-book, Dragon Fall -parodia de Dragon Ball confeccionada por Nacho Fernández y Álvaro López- es un inesperado éxito de ventas que, por entonces, rivaliza incluso con algunos títulos del mercado comercial. Consciente de sus limitaciones, Camaleón genera una distribuidora propia con la que llega exclusivamente a librerías especializadas, que a partir de entonces -con la creciente desaparición de productos de cómics de quiosco-, se convierte en el lugar casi único para la adquisición de cómics. Entre 1993 y 1995 Camaleón Ediciones publicará otros comic-book, como Mondo Lirondo (1993), de La Penya (J osé Miguel Álvarez, Albert M onteys, Ismael Ferrer y Álex Fito) o Mr. Brain presenta (1993), de Pep Brocal, Manel Fontdevila y Padu. En realidad, Camaleón ejercía de editor y distribuidor de obras en ocasiones financiadas por sus propios creadores, que obtenían unos royalties de las

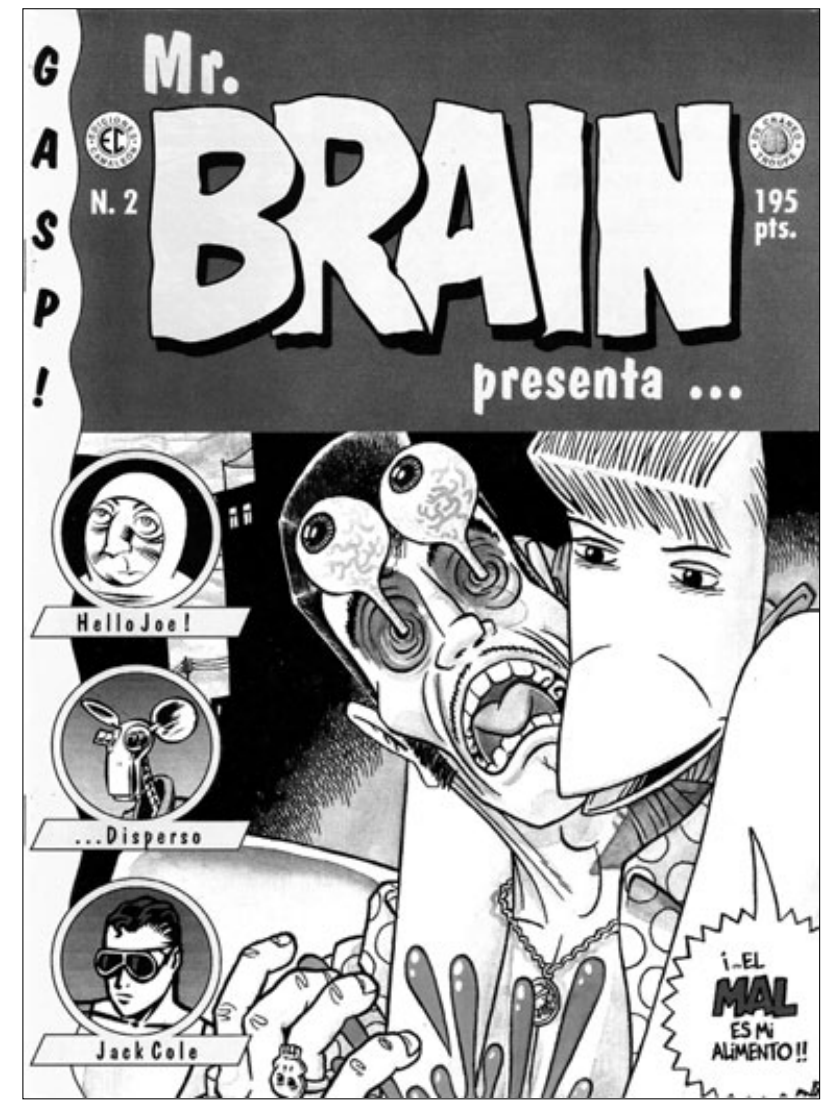

Imagen 17. El comic-book fue, desde 1993, el formato más popular entre los jóvenes autores españoles; portada del $n^{o} 2$ de Mr. Brain presenta (1993), realizada por Manel Fontdevila. 
ventas de sus productos; el sistema funcionó, siempre dentro de un orden que difícilmente sobrepasaba ventas de 2.000 o 3.000 ejemplares, excepto en el caso de Dragon Fall.

También Ediciones Glénat España, con Joan Navarro al mando, apostó por el comic-book a partir de 1994. Al principio, básicamente con productos ya conocidos, con reediciones adaptadas a este formato, de títulos como Torpedo 1936 (Enrique S. Abulí y Jordi Bernet, 1994), Nacido salvaje (Óscar Aibar y Fernando de Felipe, 1994), By Vázquez (Manuel Vázquez, 1995) o Kraken (Antonio Segura y Jordi Bernet, 1995), aunque también incluyó obras inéditas, como Amura (Sergio García, 1995) o la colección 1 de 1 (con Óscar Aibar, Miguel Ángel Martín, Elías Sánchez, Josep Busquet o Gallardo, 1995). El comic-book fue, a partir de 1995 y hasta la aparición de la novela gráfica, uno de los formatos más populares en la industria de la historieta española, con todas las ventajas e inconvenientes que ello conlleva. Ventajas: formato comercial y de producción económica, tiradas ajustadas y por tanto pérdida menores, y punta de lanza para la promoción de autores jóvenes; inconvenientes: paginación limitada por número, difícil competencia con títulos de Marvel o DC, y escasas ganancias para los autores, por lo que como producto para generar material original estaba limitado a creadores sin demasiada experiencia y sin créditos previos para darse a conocer de cara al lector.

\section{¿Y LOS NIÑNos?}

El mercado de la historieta infantil y juvenil, al menos hasta 1986 , no tenía un solo nombre, pero casi. Aunque revistas clásicas como TBO, Jaimito y Pumby aguantaron la agresiva política comercial de Editorial Bruguera hasta 1983 las dos primeras y 1984 la última, es esta empresa barcelonesa la que acapara los quioscos hasta su cierre. Entre 1970 y 1986 hubo varios intentos de consolidar títulos por parte de editoriales como Tuc, Editoria Mundis, Ediciones Druida, Sarpe o Ediciones Junior, que se ocuparon tanto de versiones españoles de cabeceras franco-belgas -como Pif, Spirou Ardilla o Fuera Borda-, como de generar cabeceras "para niñas" - Jana- 0 revistas de calidad que mezclaban autorías foráneas con las de humoristas nacionales -Jauja 0 Guai!-. Ninguna de ellas pasó de los dos años de vida, a excepción de Guai!, que forjada por Junior para asumir la presencia de un Francisco Ibáñez que había abandonado Bruguera en 1985, fue finalmente adquirida por Ediciones B, que asumió el legado de Bruguera en 1987. Ninguna de ellas puso en apuros a las decenas de cabeceras generadas por Bruguera entre 1970 y 1986 -y no por falta de méritos-, pero la apisonadora empresarial de esta editorial no dejó huecos. Fue precisamente en la década de los setenta cuando los tebeos de Bruguera alcanzaron sus tiradas más espectaculares -entre 150.000 y 300.000 ejemplares-, pero el exceso de títulos, en muchas ocasiones confeccionados con retales antiguos, la sensación de fabricación en serie de muchas páginas, el creciente desinterés de la empresa por sus revistas infantiles y juveniles, la crisis del petróleo y la interna de Bruguera y, sobre todo, el

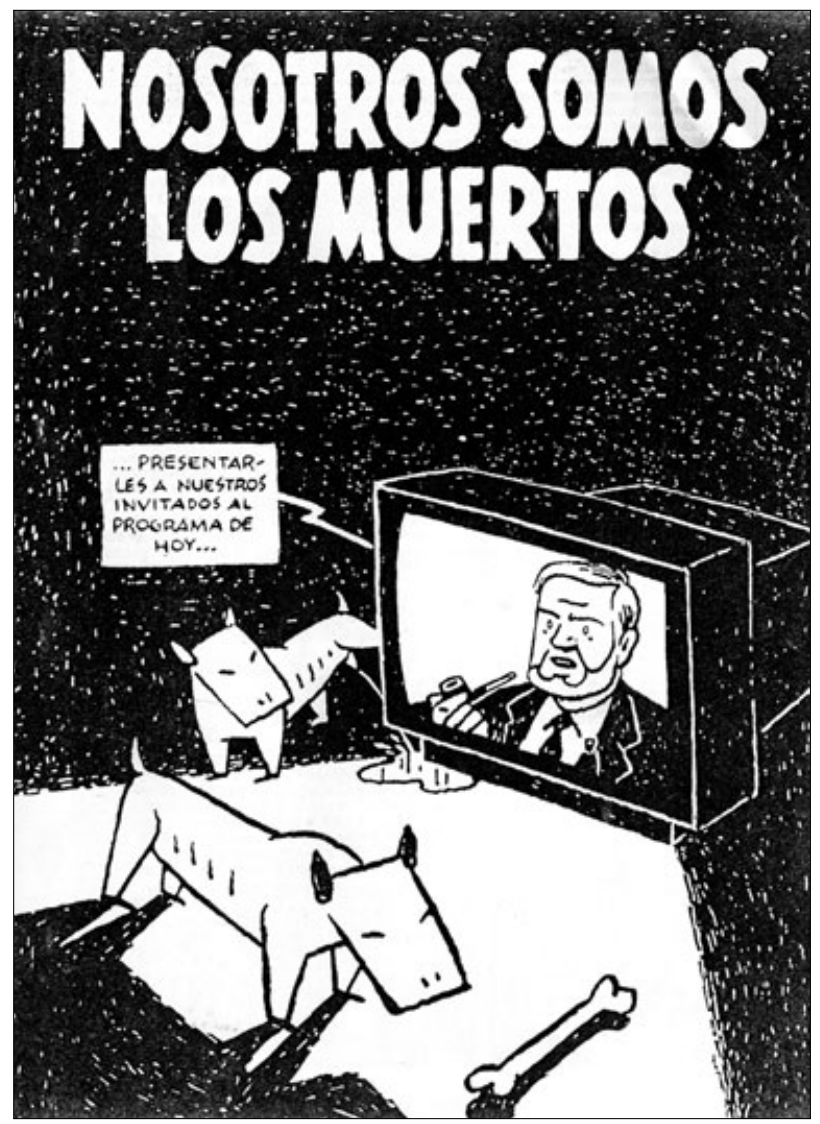

Imagen 18. El $n^{\circ}$ o de Nosotros somos los muertos (1993) fue una cruda denuncia de la indiferencia generada en Occidente hacia la guerra de los Balcanes; incluye una historieta de Max y textos de Pere Joan y de Emilio Manzano.

ARBOR CLXXXVII 2EXTRA 2011 183-208 ISSN: 0210-1963

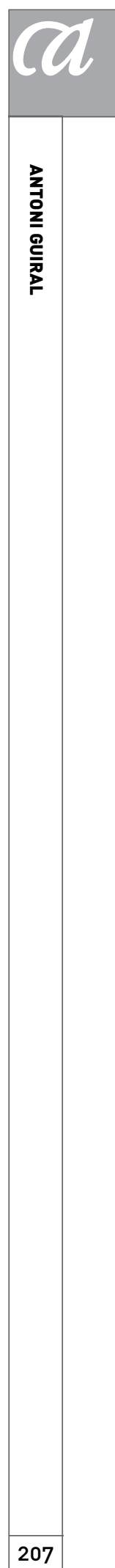


hecho de que los jóvenes lectores, ahítos de televisión, no encontraban en esas publicaciones historietas modernas hechas a su medida, acabó con el gigante empresarial en 1986. Ediciones B recogió el testigo en 1987, volviendo a poner a la venta algunas de las cabeceras de Bruguera, y aunque hubo intentos serios de confeccionar historietas acordes a los tiempos, la sección de revistas echó el cierre en 1996. Tal vez, de forma natural e irremediable, había finalizado una etapa porque así lo exigían los tiempos, pero lo cierto es que la desaparición de Bruguera fue un aviso claro de que la historieta infantil industrial estaba en peligro, lo que se confirmó diez años después. Los quioscos se habían quedado sin revistas infantiles y juveniles, salvo excepciones distribuidas en otros ámbitos - como la valenciana $\mathrm{Ca}$ macuc, aparecida en 1984, o las ya clásicas Cavall Fort y Tretzevents en Catalunya-, lo que supuso la pérdida de un lector básico para el futuro de la industria del medio.

El funeral de las revistas de cómics para adultos fue, en realidad, parcial. Algunos profesionales inquietos intentaron devolver la gloria a este formato, esta vez con un planteamiento nuevo y casi revolucionario, con historietas cortas y completas de autores de diversos países, creadores personales e intransferibles que hallaban un hueco para manifestar sus inquietudes artísticas y personales. Así lo hizo la breve Medios Revueltos (1988) y sobre todo Nosotros somos los muertos, a cuyo no 0 , realizado por Max y Pere Joan en 1993, siguió un no 1 en 1995, esta vez con vocación de continuidad, en una publicación medida, elegante y sobre todo clarificadora en el sentido de que la historieta posee un sinfín de posibilidades estéticas y narrativas que están todavía por descubrir.

Y aunque el mercado español de la historieta, en 1995, no pasaba por sus mejores momentos al menos para los autores del país, con el tiempo ha sabido reinventarse, aunque sea parcialmente, dando síntomas de querer sobrevivir. Un proceso que queda en manos, sobre todo, de autores y de editores.

\section{NOTAS}

1 En algunos casos sus firmas fueron eliminadas, entre otros detalles para en ciertos países evitar problemas con sindicatos o miembros autóctonos de la profesión.

2 Entre finales de los años sesenta y principios de los setenta, la nómina de historietistas españoles colaborando en revistas franco-belgas era impresionante. He aquí algunos de ellos: Antonio Parras, Julio Ribera, José Larraz, Juan Arranz, Manfred Sommer, Gabi, Coq, Cabrero Arnal, Florenci Clavé, Tomás Marco, Alfonso
Font, Víctor de la Fuente, Enric Sió o Pedro Alférez.

3 Mientras Trinca publicaba textos sobre elefantes 0 las civilizaciones antiguas, Pilote abría sus páginas a la Revolución de Octubre en la URSS, por no hablar de su sección de actualidad social y política.

4 Co \&t Co atesoró, entre otras, obras de excelente nivel como El artefacto perverso, de Felipe Hernández Cava y Federico del Barrio o Hot LA, de Horacio Altuna.

5 En Viñetas Manuel Vázquez publicó su primera obra larga y última historieta, Las inefables aventuras de Vázquez, agente del fisco.
Recibido: 13 de septiembre de 2010
Aceptado: 29 de noviembre de 2010 